Article

\title{
Saracatinib, a Src Tyrosine Kinase Inhibitor, as a Disease Modifier in the Rat DFP Model: Sex Differences, Neurobehavior, Gliosis, Neurodegeneration, and Nitro-Oxidative Stress
}

\author{
Meghan Gage, Marson Putra, Logan Wachter, Kylie Dishman, Megan Gard, Crystal Gomez-Estrada \\ and Thimmasettappa Thippeswamy *(D)
}

Citation: Gage, M.; Putra, M.; Wachter, L.; Dishman, K.; Gard, M.;

Gomez-Estrada, C.; Thippeswamy, T. Saracatinib, a Src Tyrosine Kinase Inhibitor, as a Disease Modifier in the Rat DFP Model: Sex Differences, Neurobehavior, Gliosis,

Neurodegeneration, and

Nitro-Oxidative Stress. Antioxidants 2022, 11, 61. https://doi.org/10.3390/ antiox11010061

Academic Editor: Domenico Nuzzo

Received: 7 November 2021

Accepted: 23 December 2021

Published: 28 December 2021

Publisher's Note: MDPI stays neutral with regard to jurisdictional claims in published maps and institutional affiliations.

Copyright: (c) 2021 by the authors. Licensee MDPI, Basel, Switzerland. This article is an open access article distributed under the terms and conditions of the Creative Commons Attribution (CC BY) license (https:/ / creativecommons.org/licenses/by/ $4.0 /)$.

\begin{abstract}
Department of Biomedical Sciences and Interdepartmental Neuroscience Program, Iowa State University, Ames, IA 50011, USA; mcgage@iastate.edu (M.G.); mrputra@iastate.edu (M.P.); lwachter@iastate.edu (L.W.); kdishman@iastate.edu (K.D.); mgard@iastate.edu (M.G.); cgomez21@stu.psm.edu (C.G.-E.)

* Correspondence: tswamy@iastate.edu
\end{abstract}

\begin{abstract}
Diisopropylfluorophosphate (DFP), an organophosphate nerve agent (OPNA), exposure causes status epilepticus (SE) and epileptogenesis. In this study, we tested the protective effects of saracatinib (AZD0530), a Src kinase inhibitor, in mixed-sex or male-only Sprague Dawley rats exposed to $4-5 \mathrm{mg} / \mathrm{kg}$ DFP followed by $2 \mathrm{mg} / \mathrm{kg}$ atropine and $25 \mathrm{mg} / \mathrm{kg}$ 2-pralidoxime. Midazolam $(3 \mathrm{mg} / \mathrm{kg}$ ) was given to the mixed-sex cohort ( $1 \mathrm{~h}$ post-DFP) and male-only cohort ( $\sim 30$ min post-DFP). Saracatinib (20 mg/kg, oral, daily for 7 days) or vehicle was given two hours later and euthanized eight days or ten weeks post-DFP. Brain immunohistochemistry (IHC) showed increased microgliosis, astrogliosis, and neurodegeneration in DFP-treated animals. In the 10-week post-DFP male-only group, there were no significant differences between groups in the novel object recognition, Morris water maze, rotarod, or forced swim test. Brain IHC revealed significant mitigation by saracatinib in contrast to vehicle-treated DFP animals in microgliosis, astrogliosis, neurodegeneration, and nitrooxidative stressors, such as inducible nitric oxide synthase, GP91 ${ }^{\text {phox }}$, and 3-Nitrotyrosine. These findings suggest the protective effects of saracatinib on brain pathology seem to depend on the initial SE severity. Further studies on dose optimization, including extended treatment regimen depending on the SE severity, are required to determine its disease-modifying potential in OPNA models.
\end{abstract}

Keywords: diisopropylfluorophosphate; saracatinib; Src family kinase; neuroinflammation; neurodegeneration; nitro-oxidative stressors; epilepsy; behavioral comorbidities

\section{Introduction}

Organophosphate nerve agents (OPNAs) pose significant threats to both military and civilian populations. These agents have previously been used in chemical warfare scenarios, such as during the Iraq-Iran war and later in terrorist attacks, which suggests that they may be used in the future [1-6]. OPNAs include a wide array of molecules, including G-series agents such as Soman (GD), Sarin (GB), and cyclosarin (GF), V-series agents such as VX and VG, GV series, and Novichok $[7,8]$. These NAs cause cholinergic toxicity through the irreversible inhibition of acetylcholinesterase (AChE), accumulation of acetylcholine (ACh) at the synapses, and overactivation of ACh receptors [9-11]. This leads to a wide variety of symptoms, such as bronchoconstriction, salivation, lacrimation, bradycardia, gastrointestinal distress, and convulsions [12-14]. OPNA poisoning, depending on the concentrations, can lead to status epilepticus (SE), a period of continuous convulsive seizures, which can initiate epileptogenesis, the development of epilepsy due to permanent brain injury in the long term [15-17]. Importantly, epilepsy is associated with spontaneously recurring seizures (SRS), gliosis, neurodegeneration, and oxidative stress, which can lead to behavioral comorbidities such as cognitive deficits, increased prevalence of depression and 
anxiety, and, in some instances, motor deficits [18-25]. Many research groups have used animal models to investigate the mechanisms of epileptogenesis following the initiation of SE by OPNAs. Diisopropylflourophosphate (DFP), an OP, is often used as a surrogate for other more potent OPNAs such as soman. Our laboratory and others have shown the development of SE and epilepsy following administration of DFP [26-32].

OPNA toxicity is typically combatted with the administration of anticholinergic drugs (antidotes) such as atropine (inhibition of ACh receptors) and oximes (reverses the aging of AChE) if administered immediately [14,33-35]. Importantly, these antidotes have only peripheral effects and do not cross the blood-brain barrier (BBB), thus having minimal effects in reversing brain toxicity [36,37]. Benzodiazepines, such as diazepam (DZP) or midazolam (MDZ), are effective in terminating behavioral SE, but when the administration is delayed, they are ineffective in preventing epileptogenesis [30,38]. Military personnel are pretreated with pyridostigmine bromide, but recent animal studies have shown no improvement in mortality or the development of SE [39-41]. Additional therapeutic targets need to be investigated for effective mitigation of the development of epilepsy and associated comorbidities following OPNA-induced toxicity.

Although ion channels have typically been the target for antiseizure and antiepileptic drugs discovery, neuroinflammation, a hallmark of epilepsy, has more recently become a therapeutic target for disease modification [24,42,43]. In this study, we explore the therapeutic potential of saracatinib (SAR, also known as AZD0530), a Src family tyrosine kinase (SFKs) inhibitor, following epileptic insult by the OPNA, DFP. SFKs are non-receptor tyrosine kinases that are involved in a wide variety of biological processes. SFKs such as Fyn and Src are expressed in the brain and mediate synaptic plasticity, long-term potentiation, cell proliferation, and neuronal modulation [44-47]. We have recently reviewed the roles of SFKs in neurological diseases [48]. In neurons, Fyn can phosphorylate metabotropic glutamate receptors (mGluR1) as well as the GluN2A and GluN2B units of N-methyl D-aspartate receptors (NMDAR) [49-51]. Our laboratory and others have shown that Fyn can also phosphorylate Tau, which can lead to translocation of the Fyn-Tau complex to the membrane to activate NMDARs [52-54]. Additionally, there is also evidence that Fyn could negatively modulate GABAergic transmission, suggesting its role in seizure generation $[55,56]$. Fyn phosphorylates PKC $\delta$ lead to the activation of the mitogen-activated protein kinase (MAPK) pathway and translocation of nuclear factor-kappa light chain enhancer $\left(\mathrm{NF}_{\kappa} \mathrm{B}\right)$ to the nucleus $[57,58]$. NFKB induces the transcription of a variety of molecules, including proinflammatory cytokines and inducers of oxidative stress [59-61]. This would suggest that inhibitors of SFKs could be beneficial in the mitigation of disease via antioxidant pathways. Fyn's role in both neuronal excitability and neuroinflammation demonstrate its utility as a possible target for the modulation of epileptogenesis [48].

The SFK inhibitor, SAR, is a small molecule that has been tested in clinical trials for cancers such as ovarian cancer and small-cell lung cancer [62,63]. More recently, it has been tested in animal models of neurological diseases such as Alzheimer's (AD) and Parkinson's disease (PD) [64-66]. It has also been tested in clinical trials of AD, though with limited efficacy [67]. Possibly, SAR administration may be more beneficial if started early in the disease onset and progression. Importantly, we have shown that SAR has the ability to cross the BBB in mice and rats as we were able to detect it in the hippocampus 5-8 h after oral administration [57]. In this study, mice pretreated with SAR had a reduction in SE severity following the challenge by kainic acid (KA). When SAR was administered to rats after the induction of SE by KA, there was a significant reduction in the occurrence of SRS [68]. Another study using pilocarpine to initiate SE in mice showed that SAR administration led to a reduction in epileptogenic spikes [69]. This suggests that SAR may also be a useful disease modifier following SE induced by an organophosphate, DFP.

We recently tested the short-term effects of SAR in animals that had about 20 min of convulsive seizures after DFP intoxication [70]. These animals did not develop SRS during the treatment period and had significantly reduced neurodegeneration compared to the VEH-treated group when tested $24 \mathrm{~h}$ after the last day of SAR treatment (i.e., 8 days 
post-DFP) [70]. Notably, the SAR-treated animals had significant weight loss compared to VEH controls. In that study, we administered $25 \mathrm{mg} / \mathrm{kg}$ SAR, beginning $4 \mathrm{~h}$ after DFP intoxication, twice daily at $12 \mathrm{~h}$ intervals during the first three days, followed by a single dose per day for the next four days [70]. In this study, we tested $20 \mathrm{mg} / \mathrm{kg}$ per day for 7 days to minimize toxicity and increase the efficacy of the drug. We also tested the shortterm ( 8 days, in both sexes) and the long-term (10 weeks, males only) impact of this dosing regimen. We hypothesize that SAR administration with this dosing regimen for a week will mitigate DFP-induced brain pathology and morbidity.

\section{Materials and Methods}

\subsection{Animal Source, Care and Ethics}

Age-matched (7-8 weeks) males and females or males only Sprague-Dawley rats were purchased from Charles River (Wilmington, MA, USA). Animals were allowed at least $72 \mathrm{~h}$ of acclimation before experiments began. The number of male and female animals sacrificed at each timepoint is outlined in Table 1.

Table 1. Number of animals by sex and sacrifice time-point. Number in parenthesis indicates mortality.

\begin{tabular}{|c|c|c|c|c|c|}
\hline Timepoint & Midazolam Administration & PBS + VEH & PBS + SAR & $\mathrm{DFP}+\mathrm{VEH}$ & $\mathrm{DFP}+\mathrm{SAR}$ \\
\hline 8 days Males & One hour post DFP & 5 & 0 & 7 & $10(20 \%)$ \\
\hline 8 days Females & One hour post DFP & 5 & 0 & 8 & $8(25 \%)$ \\
\hline 10 weeks Males & After $20 \min C S$ & 14 & 14 & 16 & $16(6 \%)$ \\
\hline
\end{tabular}

Procedures were approved by the Iowa State University Animal Care and Use Committee (IACUC-21-109). Animals were provided ad libitum access to food and water by animal care staff at the Iowa State University Laboratory of Animal Resources. Animals were single-housed, and males and females were kept in separate rooms with temperatures between $19-22{ }^{\circ} \mathrm{C}$. Animals were randomized for DFP or phosphate-buffered saline (PBS) injection. At the end of the experiment, animals were euthanized with $100 \mathrm{mg} / \mathrm{kg}$ pentobarbital sodium (in euthanasia solution, i.p.) as per the American Veterinary Medical Associations Guidelines for the Euthanasia of Animals. All procedures complied with the ARRIVE guidelines [71].

\subsection{Chemicals and Reagents}

DFP (Sigma-Aldrich, St. Louis, MO, USA; >97\% purity by GC-MS) was prepared fresh in cold $0.1 \mathrm{M}$ PBS 5 min prior to administration and kept on ice throughout the experiment. Atropine sulfate (ATS, Thermo Fisher Scientific, Waltham, MA, USA) and pralidoxime (2-PAM, Sigma Aldrich) were also prepared in saline just prior to administration and kept at room temperature. MDZ and euthanasia solution were purchased from the Iowa State University Lloyd Veterinary Medical Center Hospital Pharmacy. Paraformaldehyde (PFA) was purchased from Acros Organics and prepared fresh (4\%) in PBS prior to perfusion. Gelatin, used for tissue embedding, consisted of the following: 15\% type A porcine gelatin, 7.5\% sucrose, $0.1 \%$ sodium azide in PBS. Citric acid buffer for antigen retrieval consisted of $10 \mathrm{mM}$ citric acid and $0.05 \%$ Tween 20, at pH 6.0. For immunohistochemistry (IHC), blocking buffer consisted of $10 \%$ donkey serum and $0.2 \%$ Triton X in $0.1 \mathrm{M}$ PBS. Antibodies were diluted in $2.5 \%$ donkey serum, $0.25 \%$ sodium azide, $0.1 \%$ Triton $X$ in $0.1 \mathrm{M}$ PBS. Streptavidin was diluted in 0.1 M PBS. Antibodies source and concentrations used are listed in Table S1. For Western blotting, radioimmunoprecipitation (RIPA) buffer and protease and phosphatase inhibitor (PPI) were purchased from Thermo Fisher Scientific. Antibodies (for Western blotting) were diluted in 1:1 blocking buffer (Licor) and $0.1 \%$ Tween 20 to reduce background. SAR was kindly supplied by AstraZeneca through the Open Innovation Program and diluted in $0.5 \%$ hydroxypropylmethylcellulose and $0.1 \%$ Tween 80 (VEH). SAR was prepared once in 3-4 days and left stirring at room temperature to prevent precipitation. SAR formulation has been described in our previous publication [70]. 


\subsection{Exposure to Diisopropylflourophosphate (DFP)}

We used a total of 103 animals in this study. We had four treatment groups as listed in Table 1; PBS + VEH, PBS + SAR, DFP + VEH, and DFP + SAR. Animals were administered $4 \mathrm{mg} / \mathrm{kg}$ (males) or $5 \mathrm{mg} / \mathrm{kg}$ (females) DFP (s.c.) or PBS as a control. DFP or PBS administration was randomized. We decided to increase the dose in females due to the increased resistance of females to develop seizures following DFP in our previous publication [26]. Immediately after the administration of DFP, animals were administered $2 \mathrm{mg} / \mathrm{kg}$ ATS and $25 \mathrm{mg} / \mathrm{kg}$ pralidoxime (2 PAM, i.m.) to reduce mortality. The experimental timeline is illustrated in Figure 1A. Around 5-10 min after DFP administration, animals began displaying behavioral seizures. We ranked these seizures using a modified Racine scale in which stages 1-2 are considered non-convulsive seizures (NCS) and stages 3-5 are considered convulsive seizures (CS) [72]. Behavioral features are described and depicted in Figure 1B. Stage one seizures involve salivation, lacrimation, urination, defecation, and mastication, while stage two involves the addition of head nodding and tremors. Stage three is characterized by rearing, forelimb clonus, and Straub tail; stage four is characterized by loss of the righting reflex, while stage five seizures are characterized by circling and repeated falling. For the 8 -day group, MDZ was administered one hour after DFP intoxication $(n=33)$. The number of animals $(n)$ used as controls, VEH, DFP with VEH/SAR are listed in Table 1 . For the 10 -week group, MDZ was administered after the animals displayed 20 min of CS $(n=32)$. For animals that did not reach 20 min of CS, MDZ was administered one hour after DFP administration. Treatments were assigned in a randomized block design based on the number of minutes in CS in order to mitigate the effects of SE severity in epileptogenesis. SAR or VEH was administered two hours after MDZ in order to account for the time it would take a patient to reach the hospital in a real-world scenario. In both groups, $20 \mathrm{mg} / \mathrm{kg}$ SAR (p.o.) or VEH was administered every $24 \mathrm{~h}$ for 7 total doses. Animals were administered saline (1 mL, s.c.) and nutrical (Midwest Veterinary Supply) twice a day for at least the first three days until the animals gained weight. Animals were handled twice a day for the duration of the treatment period and were assessed for the occurrence of SRS (induced due to handling) and morbidity.

A.

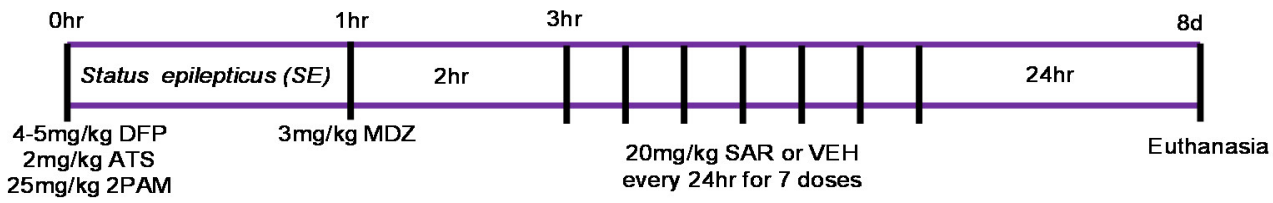

B.

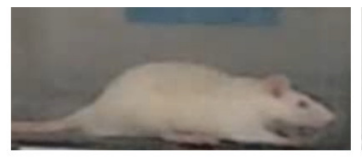

Stage 1

Mastication, salivation lacrimation, urination, defecation

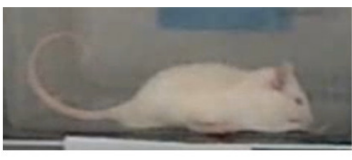

Stage 2 Head nodding, wet dog
tremors, neck jerks

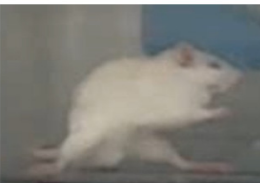

Stage 3

Standing on hind limbs forelimb clonus, Straub tail, rearing

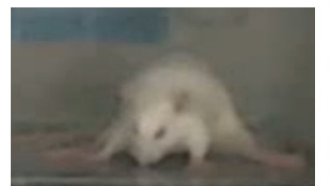

Stage 4

Loss of righting reflex forelimb clonus

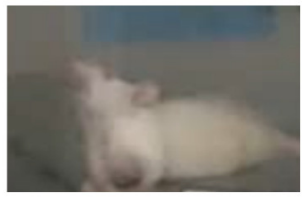

Stage 5

Abducted limbs repeated jumping and falling, sometimes circling

Figure 1. Experimental design and seizure staging for short time-point studies (day 8 post-DFP). (A) Male and female rats were exposed to $4 \mathrm{mg} / \mathrm{kg}$ and $5 \mathrm{mg} / \mathrm{kg}$, diisopropylfluorophosphate (DFP), respectively, followed $1 \mathrm{~min}$ later by $2 \mathrm{mg} / \mathrm{kg}$ atropine sulfate (ATS) and $25 \mathrm{mg} / \mathrm{kg}$ pralidoxime (2-PAM). Most animals started to display seizure activity within 5-10 min of DFP intoxication (status epilepticus-SE). One hour later, $3 \mathrm{mg} / \mathrm{kg}$ midazolam (MDZ) was administered followed two hours later by $20 \mathrm{mg} / \mathrm{kg}$ saracatinib (SAR) or vehicle (VEH). SAR or VEH was administered once a day for 7 days. $24 \mathrm{~h}$ after the last dose, animals were euthanized for immunohistochemical analysis. (B) Behavioral seizures of each stage (1-5) are described. During SE, animals were assessed in real-time for the seizure severity. 


\subsection{Modified Irwin Scoring for Morbidity Analysis}

$24 \mathrm{~h}$ after DFP exposure, animals were assessed using a modified version of the Irwin scale $[73,74]$. We evaluated a total of ten parameters; a point was given for the presence of each parameter. The parameters are as follows: ocular changes such as exophthalmos, porphyrin (bulged eyes and staining around the eyes) and lacrimation, hunched body posture, tremors, jumpiness (unprovoked or when probed by experimenter), muscle weakness (tail rigidity), aggression (actively trying to bite experimenter during handling), diarrhea, change in fur color, and piloerection. In addition, we also recorded when animals had SRS during handling for the first seven days. The animals were each handled twice a day.

\subsection{Behavioral Evaluation}

Epilepsy is associated with a variety of behavioral comorbidities. The animals were rested for 6 weeks after DFP exposure, prior to behavioral testing, to allow progression of epileptogenesis. One day rest was given between each test. Prior to experimentation, animals were left to acclimate to the testing environment. Two experimenters conducted the behavioral testing so that the handling was performed by the same person throughout the experiment. The ANY-maze video-tracking software (Stoelting Co., Wood Dale, IL, USA) was used to measure various parameters.

\subsubsection{Novel Object Recognition}

The apparatus consisted of a square $100 \mathrm{~cm} / 100 \mathrm{~cm}$ box. One day prior to testing, animals acclimated to and explored the empty apparatus for $10 \mathrm{~min}$. Between each animal, the apparatus was sterilized with $70 \%$ ethanol to counter the influence of animal odor. On the next day, animals were placed into the apparatus for 5 min with two identical objects placed in opposite corners of the apparatus. Importantly, animals were released from a corner opposite to either object. Four hours later, animals were placed in the same apparatus for $5 \mathrm{~min}$ with one of the familiar objects and a novel object. The time spent with each object was measured. In order to gain a sense of long-term memory, $24 \mathrm{~h}$ later, we placed the animals into the apparatus with the first familiar object and a second novel object for $5 \mathrm{~min}$. Importantly, animals that spend more time with the novel object are presumed to remember the old object; thus, this test measures learning and cognition [75]. We also placed a separate group of normal animals $(n=8$, Figure S1) into the apparatus with all three objects and found that there was no statistical difference in the time the animals spent with each object (Note: these 8 animals are not included in Table 1 since they were not used in this study except for the validation purpose).

\subsubsection{Horizontal Bar Test}

The apparatus consisted of a wooden bar ( $80 \mathrm{~cm}$ long), $60 \mathrm{~cm}$ above a table surface. The animal was released from one end of the bar and trained (by the experimenter pushing the animal) to walk to a safety box at the other end of the bar. On the first day, a $4 \mathrm{~cm}$ wide beam was used, and four consecutive trials were given. The same procedure was repeated on the second day. On the third day, the 4 trials were conducted using a $2 \mathrm{~cm}$ wide bar. Three hours later, the animal was then tested in the same manner on a $1 \mathrm{~cm}$ bar. For each trial period, the time to reach the platform, number of times the experimenter needed to push the animal, and number of footslips (foot not being placed correctly on the bar) were measured.

\subsubsection{Rotarod}

Animals were placed in groups of four onto a rotating rod (AccuRotor 4 channel, Omnitech Electronics Inc., Columbus, OH, USA) $36 \mathrm{~cm}$ above a surface. Animals were placed onto the rod $(7 \mathrm{~cm}$ diameter; initial velocity $10 \mathrm{rpm}$ ) and accelerated to $60 \mathrm{rpm}$ over 2 min. The acquisition software, Fusion 6.2, detected and recorded the time took for an animal to fall from the rotating rod. Latency to fall was considered a measure of motor ability. Animals were given three trials a day for two days, followed by a test. 


\subsubsection{Morris Water Maze (MWM)}

The apparatus consists of a black circular tank $(180 \mathrm{~cm}$ diameter, $60 \mathrm{~cm}$ high) filled with water $\left(23-26{ }^{\circ} \mathrm{C}\right)$. The tank was divided into four quadrants (SE, SW, NW, NE) which each had a distinct visual cue above the water. Animals are required to find an invisible (plexiglass) platform (submerged $2-3 \mathrm{~cm}$ below the water) in the tank. Over time, animals learn to associate the location of the platform with visual cues. This requires spatial learning and memory, which can be impaired in epileptic rats [76]. On the first day, the platform was placed in the middle of the tank approximately an inch above the water, so that the animals could see the location of the platform. This training encourages exploration in the tank and helps the animals to learn that the platform is in the tank. Animals were given four trials with a maximum time of $120 \mathrm{~s}$ with inter-trial intervals of 25-30 min. On the next day, the platform was hidden under the water in one of the quadrants (target quadrant). Animals were again given four trials with a maximum of $120 \mathrm{~s}$ with 25-30-min inter-trial intervals. Animals were released from a different quadrant for each trial; the order of the quadrants was randomized between animals. The training protocol with the submerged platform was repeated for 5 more days. Then, $24 \mathrm{~h}$ after training, the platform was removed from the apparatus. Animals were released from the opposite quadrant to the target quadrant and allowed to swim for $60 \mathrm{~s}$. The amount of time spent in the target quadrant indicates the impact of treatment (DFP and SAR/VEH) on memory.

\subsubsection{Forced Swim Test}

The forced swim test is considered a measure of depression and anxiety [77]. Animals are placed into a large cylinder $\left(54 \mathrm{~cm}\right.$ tall, $28 \mathrm{~cm}$ diameter) filled with water $\left(23-26^{\circ} \mathrm{C}\right)$. Animals were placed in the water and allowed to acclimate for $2 \mathrm{~min}$. For $4 \mathrm{~min}$ after the acclimation period, the degree of immobility was measured by ANY-maze software. Increased immobility is considered to be a marker of increased depression and anxiety.

\subsection{Immunohistochemistry}

Animals were perfused with $0.1 \mathrm{M}$ PBS for $2 \mathrm{~min}$, followed by $4 \%$ PFA in $0.1 \mathrm{M}$ PBS for 15-20 min. Following perfusion, brains were incubated in PFA for $24 \mathrm{~h}$ before transferring to $25 \%$ sucrose in $0.1 \mathrm{M}$ PBS. Brains were then gelatin embedded overnight prior to freezing with liquid nitrogen and cooling with isopentane before storing at $-80^{\circ} \mathrm{C}$. Brains were sectioned coronally and serially at $16 \mu \mathrm{m}$ thick so that each slide contained $4-5$ sections approximately $480 \mu \mathrm{m}$ apart $[78,79]$. A total of $4-5$ sections were used for each immunohistochemical stain. Sections were stored at $-20^{\circ} \mathrm{C}$ for long-term use. For antigen retrieval, slides were immersed in citric acid buffer at $90-95^{\circ} \mathrm{C}$ for $23 \mathrm{~min}$ and then left to cool for $30 \mathrm{~min}$. Slides were mounted onto Shandon cover plates and then placed in Shandon racks and washed with PBS for an hour. Slides were incubated with blocking buffer for an hour prior to incubation with primary antibodies overnight at $4{ }^{\circ} \mathrm{C}$. The next day, slides were cooled for 15 min before washing with PBS for an hour. Slides were then incubated with appropriate biotinylated or alexaflour conjugated secondary species antibodies for an hour. After washing with PBS for another hour, slides were then incubated with streptavinin-CY3 for an hour, followed by another hour of washing with PBS. For flourojade B (FJB) staining, slides were washed with distilled water before incubation in $0.006 \%$ potassium permanganate for $5 \mathrm{~min}$. After washing with distilled water, slides were immersed in $0.0003 \%$ FJB in $0.1 \%$ acetic acid for $10 \mathrm{~min}$ and dehydrated with xylene. Slides were then mounted with vectashield containing DAPI or Surgipath acrytol and stored in the fridge until imaged.

Two microscopes were used to image the hippocampus (Cornu Ammonis 1 (CA1), Cornu Ammonis 3 (CA3), and dentate gyrus (DG), piriform cortex (PC), and amygdala (AMY)). For NeuN-FJB staining, we used the Axiovert 200 Zeiss inverted fluorescence microscope with the Hammamatsu camera. Other stains were imaged with the Leica DMi8 microscope with the Leica K5 camera. Image J (FIJI) was used to manually quantify IBA1, GFAP, CD68, FJB, iNOS, 3NT and GP91 ${ }^{\text {phox }}$ positive cells; experimenters were blind to 
the treatment group at the time of quantification. DAPI was used in order to confirm the presence of various molecules inside of cells. We counted from at least 4 sections for each staining/animal, and when calculating the total number of cells, we considered the average between the sections.

\subsection{Western Blotting}

Following euthanasia with sodium pentobarbital, brains were dissected to extract the PC-AMY region. Following dissection, tissues were snap-frozen in liquid nitrogen and stored at $-80^{\circ} \mathrm{C}$. Lysates were prepared by homogenizing the tissues in RIPA buffer $(1 \mu \mathrm{g} / \mu \mathrm{L})$ containing $0.1 \%$ protease and phosphatase inhibitors. Lysates were then sonicated and centrifuged for an hour at 10 RCF. A Bradford protein assay was used to determine the volume required for 30-60 $\mu \mathrm{g} /$ sample. Samples (containing protein and sample buffer) were added to wells of an SDS-PAGE gel (8-10\%). An amount of 2Ml molecular weight marker was used in a separate well to determine the size of the proteins. SDS-PAGE was run for $\sim 2 \mathrm{~h}$ at $100 \mathrm{Mv}\left(4^{\circ} \mathrm{C}\right)$. Gels were transferred (wet) onto a nitrocellulose membrane for $16 \mathrm{~h}$ at $4{ }^{\circ} \mathrm{C}$, washed, and blocked for an hour. Membranes were incubated overnight in primary antibodies followed by washing in PBS containing $0.1 \%$ Tween 20 (PBST) for an hour. Appropriate IR dye-conjugated secondary antibodies were used to detect the primary antibody with incubation for an hour followed by another hour washing in PBST. A similar method was used with housekeeping control protein, $\beta$-actin (incubation for an hour with both primary and secondary antibodies). Odessey IR imaging system and Image studio Lute were used to visualize and analyze protein concentrations.

\subsection{Experimental Design, Methodological Rigor, and Statistics}

Extreme care was taken to maintain the integrity of the research. Importantly, we randomized treatment in a way that seizure severity was matched across treatment groups. Where appropriate, experimenters were blind to the treatment group. We utilized the Grubbs' test to identify outliers and the Shapiro-Wilk test to assess normality. A linear mixed model was used to determine the effects of sex on various parameters in different brain regions. A simple linear regression model was used to determine the correlation between the markers of oxidative stress and the number of reactive microglia and astrocytes in each treatment group. Graphing and statistical procedures were performed using Graphpad Prisim 9.0. Specific statistics details can be found in the corresponding figure legends. $p$-values of $<0.05$ were considered statistically significant.

\section{Results}

\subsection{Impact of DFP and SAR Treatment: SE Severity, Weight Loss, SRS, and Mortality}

We challenged males with $4 \mathrm{mg} / \mathrm{kg}$ and females $5 \mathrm{mg} / \mathrm{kg}$ DFP, or an equal volume of VEH, followed by $2 \mathrm{mg} / \mathrm{kg}$ ATS, $25 \mathrm{mg} / \mathrm{kg}$ 2-PAM (immediately) and MDZ (after one hour). There were no differences in the initial SE severity between animals that were used to treat with SAR or VEH or for either sex, nor were there sex differences (Figure 2A). None of the VEH-treated males or females died, while 2/10 males ( 2 and 6 days post-DFP) and $2 / 8$ females ( 2 and 4 days post-DFP) treated with SAR died. Further, $28 \%$ of VEHtreated males $(n=7)$ and $25 \%$ of VEH-treated females $(n=8)$ had at least one CS during handling compared to none in SAR-treated males $(n=8)$ and 17\% in SAR-treated females $(n=6)$ (Figure 2B). The differences were not significantly different between VEH- and SARtreated animals. DFP intoxication led to significant weight loss for the first 3-4 days postexposure in both males and females, and SAR treatment had no effect (Figure 2C,D). We also compared males and females in each treatment group (Figure 2E-G). Male controls gained weight significantly quicker than female controls (Figure 2E). There were no differences in weight loss between sexes for DFP-treated animals, with the exception of the first day of DFP and SAR males compared to DFP and SAR females (Figure 2G). 

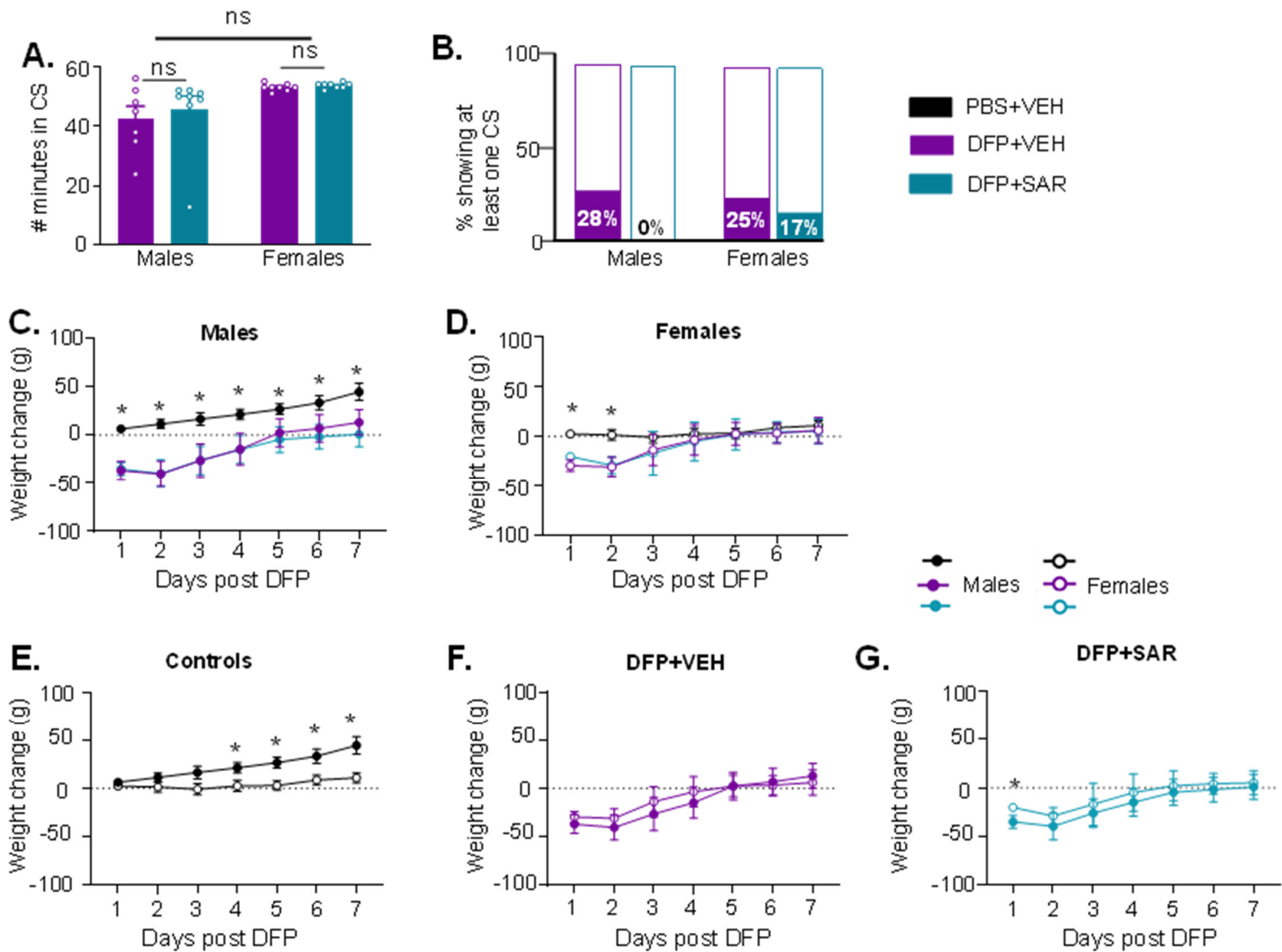

Figure 2. Initial seizure (SE) severity and morbidity measures during the treatment period for animals with $1 \mathrm{~h}$ between DFP exposure and midazolam treatment. (A) There was no statistical difference in the amount of time spent in CS during SE between animals treated with saracatinib (SAR) or vehicle $(\mathrm{VEH})$ in either sex or between sexes ( $t$-test, $n=6-8$ ). (B) $28 \%$ of VEH treated males and $25 \%$ of VEH treated females had at least one CS when handled during the treatment period compared to none in SAR treated males but $17 \%$ in SAR treated females (Fisher's exact). (C,D) All DFP treated males and females had significant weight loss compared to controls ( $n=5-8$, mixed measures ANOVA). (D) Control males (PBS + VEH) gained weight significantly faster than female controls but there was no difference in the DFP animals regardless of VEH or SAR treatment. (E-G): Weight change comparison between males and females in controls, DFP + VEH, and DFP + SAR. ${ }^{*} p<0.05, n=5-8$, mixed measures ANOVA.

\subsection{Impact of DFP Toxicity and SAR Treatment on Short-Term (8 Days) Gliosis and Neurodegeneration}

We used a linear mixed model to consider treatment and the location in the brain. In order to evaluate sex differences on a more holistic basis, we pooled data from all hippocampal regions (CA1, CA3 and DG) as well as data from the PC and AMY. A linear mixed model was also used to determine the effects of sex on various parameters. Since the initial SE severity between sexes was not significantly different (Figure 2A), it is therefore appropriate to compare males and females across the various parameters.

\subsubsection{Microgliosis}

The number of IBA1 positive cells, the number of CD68 positive cells, and the number of IBA1 positive cells with reactive morphology (M1-like) were quantified. Reactive 
microglia have large cytoplasm and short processes in contrast to non-reactive microglia, which have small cell bodies and long processes [80]. Representative images of IBA1 and CD68 from CA1 of the hippocampus and the AMY are presented in Figure 3A. As expected, we found significant upregulation of IBA1 positive cells in DFP- and VEH-treated males and females compared to respective control in all regions of the brain (Figure 3B,E). This was not significantly mitigated by SAR in most regions except in the AMY in females (Figure 3E). There was also a significant upregulation of the percent of IBA1 positive cells with CD68 in DFP-treated males and females (both SAR and VEH) compared to controls in the DG, PC, and AMY (Figure 3C,F). There was also a significant upregulation of the number of IBA1 positive cells with reactive morphology in the PC and AMY (Figure 3D,G). Overall there were minimal sex differences in the number of IBA1 positive cells, percent cells with CD68, and the number of reactive-like microglia (Figure 3H-J). The only significant difference was in the percent cells with CD68, in which females had significantly less than males in the PC/AMY region in the SAR-treated group (Figure 3I).

\subsubsection{Astrogliosis}

We counted the total number of GFAP positive cells and the number of GFAP positive cells with reactive morphology. Reactive cells had retracted processes and large cell bodies [81]. Representative images of astrogliosis in the hippocampus (CA1) and AMY from both male and female groups are shown in Figure 4A. Interestingly, DFP and SAR treatment did not lead to a significant change in the number of GFAP positive cells with the exception of DFP and VEH males in the PC (Figure 4B,D). However, in males, all regions of the brain had significant upregulation in reactive astrocytes by DFP and significant reduction by SAR treatment in the hippocampal regions (Figure 4C). In females, there was also an increase in GFAP positive cells with reactive morphology, but the mitigation by SAR was not as significant as in males (Figure $4 \mathrm{E}$ ). There were no significant sex differences in the hippocampus or AMY/PC region for the number of GFAP positive cells or the number of GFAP positive cells with reactive-like morphology in any treatment group (Figure $4 \mathrm{~F}, \mathrm{G}$ ).

\subsubsection{Neurodegeneration}

We found FJB positive cells that were colocalized with NeuN as well as FJB positive cells without NeuN positive staining, as reported in our previous publication [70]. We counted both colocalized cells and FJB cells without NeuN in our assessment of neurodegeneration since NeuN was expected to downregulate in some neurons in response to stress [82]. Representative images from the hippocampus (CA1) and AMY are shown in Figure 5A. DFP-treated males and females had increased FJB positive cells in all regions of the brain, though it was only significant in some regions (Figure 5B,C). This was not significantly mitigated by SAR treatment. There were no sex differences in the number of FJB positive cells for any group in any brain regions investigated (Figure 5D).

\subsection{DFP and SAR Effects in Animals with 20 min of Continuous CS (SE): Weight Loss, Mortality, SRS, and Morbidity}

Since severe SE with continuous CS lasting for $>40 \mathrm{~min}$ seems to have caused a significant brain injury and limited mitigation by SAR (one-week treatment), we tested its efficacy in animals with $\sim 20 \mathrm{~min}$ of SE. The experimental design is presented in Figure 6A.

Importantly, there was no difference in the duration of CS during SE between VEHand SAR-treated animals (Figure 6B). None of the animals $(n=16)$ in the DFP and VEH group died, while one of the animals in the DFP and SAR group died about $24 \mathrm{~h}$ after MDZ (1/16). Notably, one of the PBS and VEH animals also died shortly after MDZ administration. DFP-treated animals (VEH and SAR) lost weight for the first 2-3 days post-DFP, which was significantly greater compared to controls (Figure 6C). We recorded when animals had SRS during animal handling (twice a day). Results showed that $37 \%$ of DFP and VEH animals and 13\% of DFP and SAR animals had at least one SRS during the treatment period (Figure 6D, not significant). We also assessed other comorbidities in 
DFP-treated animals based on a modified Irwin scale at $24 \mathrm{~h}$ post-DFP; at the time, only one dose of SAR or VEH had been administered. SAR-treated animals had lower Irwin scores $(21.4 \%)$ than VEH-treated animals, though the difference was not significant (Figure 6E).
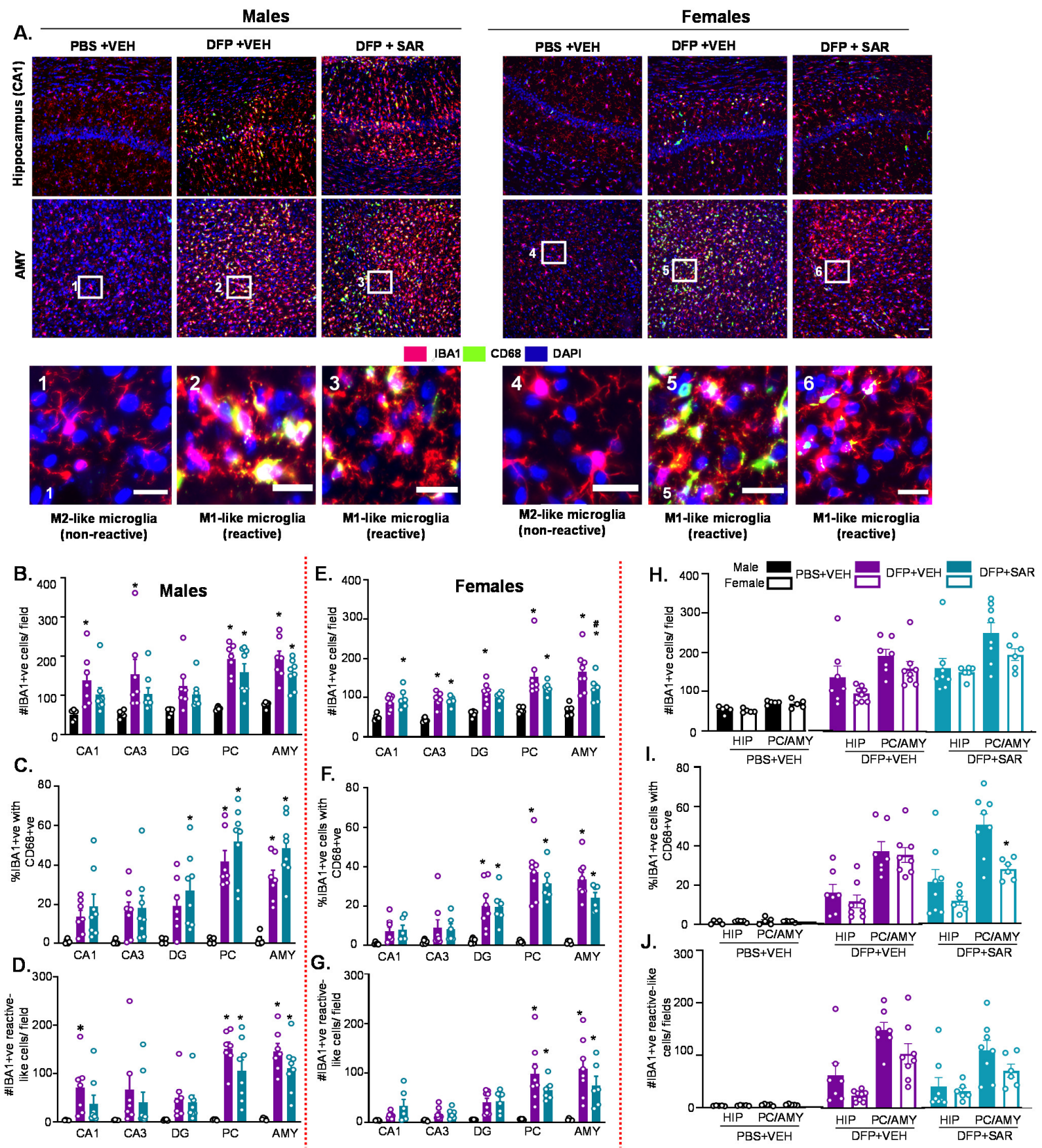

Figure 3. Microgliosis at day 8 post-DFP. (A) Representative images of IBA1 and CD68 positive cells (immunohistochemistry-IHC) from each treatment group. Scale, $50 \mu \mathrm{m}$ for whole field $\left(0.44 \mathrm{~m}^{2}\right)$ images and $25 \mu \mathrm{m}$ for boxed images (1-6). (B-J) Cell quantification. (B,E) Number of IBA1 positive cells. (C,F) Percent IBA1 positive cells colocalized with CD68 positive cells. (D,G) Number of IBA1 positive cells with reactive-type morphology. Reactive cells were considered to have large cell bodies and retracted processes. (H-J) Averages were pooled from the hippocampus (CA1, CA3 and DG) as well as the PC and AMY to compare sex differences for all microgliosis parameters. For all, $n=5-8$, mixed measures ANOVA. ${ }^{*} p<0.05$ compared to controls and $\# p<0.05$ compared to DFP + VEH (B-G). ${ }^{*} p<0.05$ males vs females $(\mathbf{H}-\mathbf{J})$. 

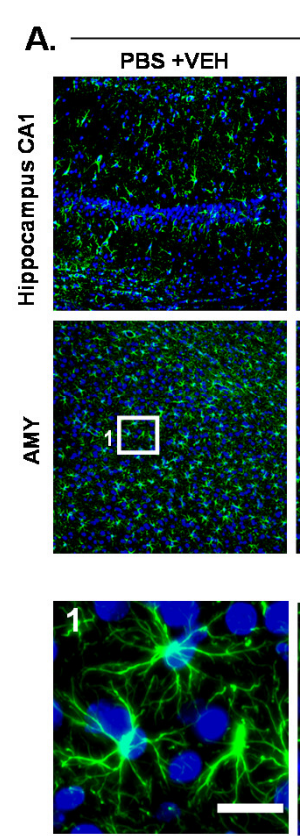

A2-like microglia (non-reactive)
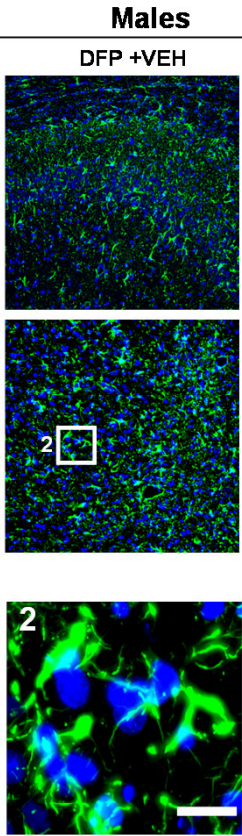

A1-like microglia (reactive)
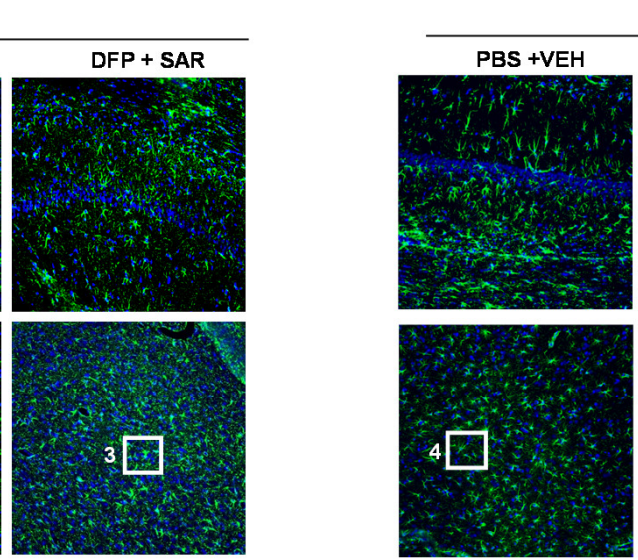

GFAP DAPI

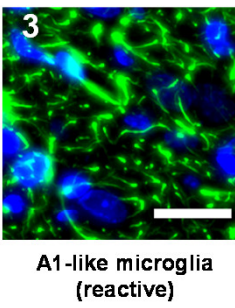

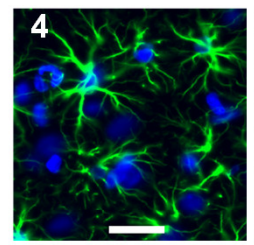

A2-like microglia (non-reactive)
Females
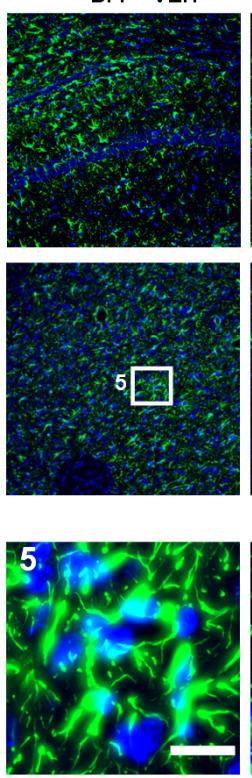

A1-like microglia (reactive)
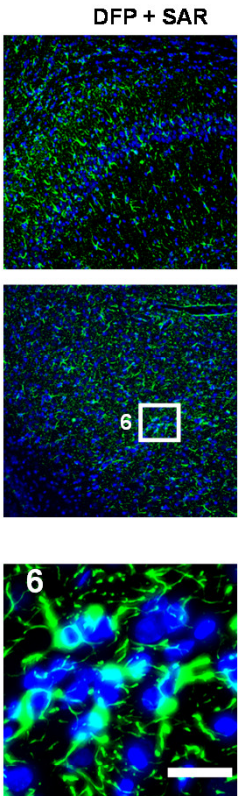

A1-like microglia (reactive)
B.

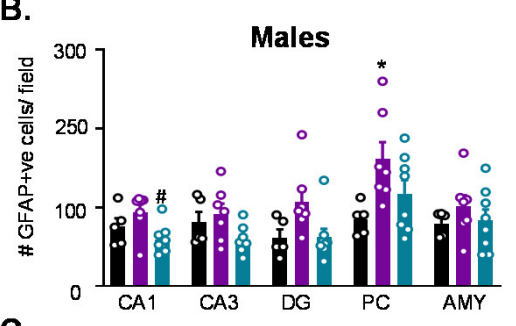

C.

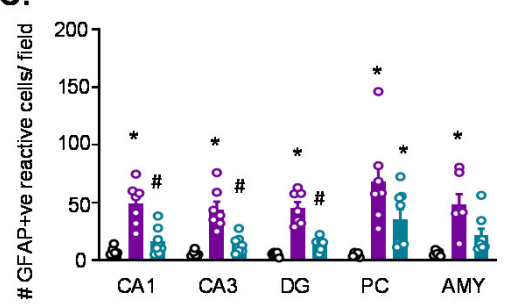

D.

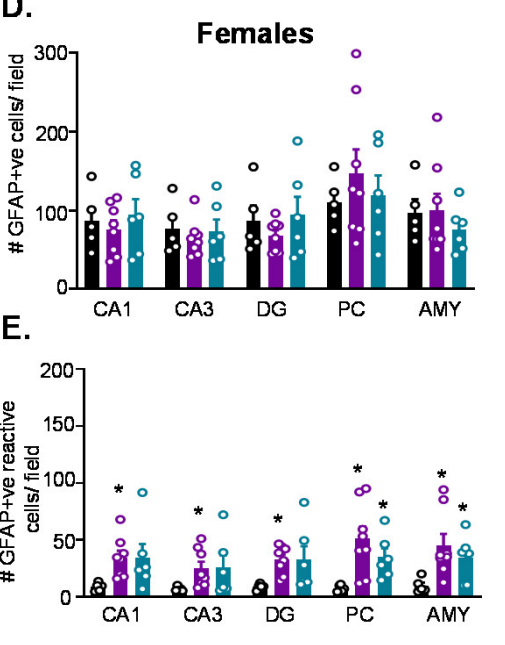

F.
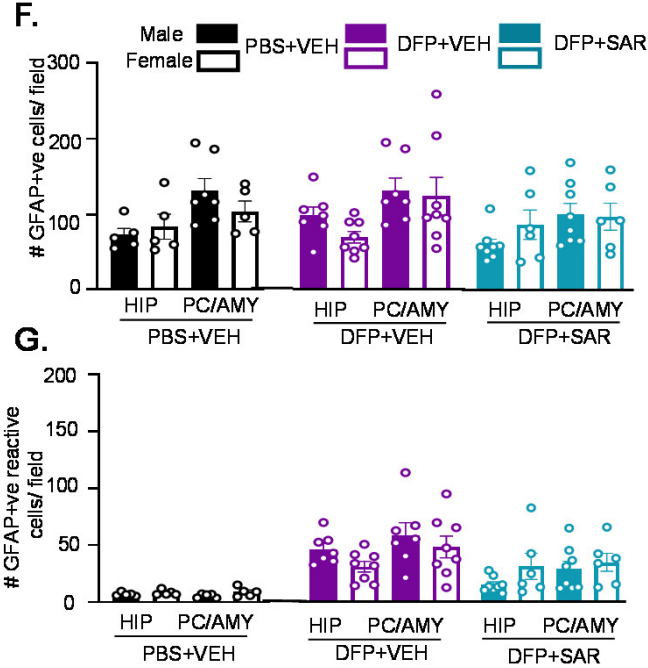

Figure 4. Astrogliosis at day 8 post-DFP. (A) Representative IHC images for GFAP positive cells from each treatment group. Scale, $50 \mu \mathrm{m}$ for whole field $\left(0.44 \mathrm{~m}^{2}\right)$ images and $25 \mu \mathrm{m}$ for boxed images (1-6). (B-G) Cell quantification. (B,D) Number of GFAP positive cells. (C,E) Number of GFAP positive cells with reactive-type morphology. Reactive cells were considered to have large cell bodies and retracted processes. $(F, G)$ Averages were pooled from the hippocampus (CA1, CA3 and DG) as well as the PC and AMY to compare sex differences for all astrogliosis parameters. For all, $n=5-8$, mixed measures ANOVA. ${ }^{*} p<0.05$ compared to controls and $\# p<0.05$ compared to $\mathrm{DFP}+\mathrm{VEH}(\mathbf{B}-\mathbf{E}) .{ }^{*} p<0.05$ males vs females $(\mathbf{F}-\mathbf{G})$.

\subsection{Impact of DFP and SAR on Behavioral Comorbidities}

Six weeks following DFP intoxication, animals were tested on a variety of behavioral apparatuses to assess learning, memory, motor ability, anxiety and depression. The order of experiments is depicted in Figure 6A. 
A.

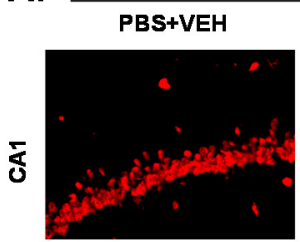

$\sum_{<}^{\gtrless}$

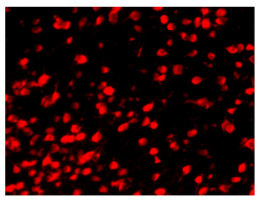

Males

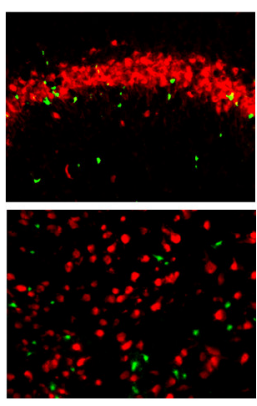

DFP+SAR

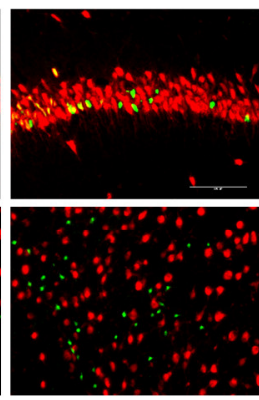

\section{Females}

PBS+VEH
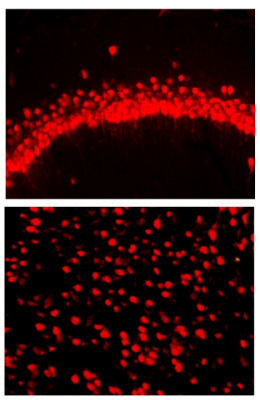

DFP+VEH

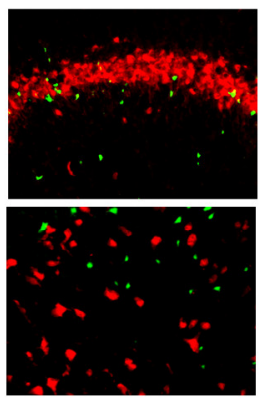

DFP+SAR

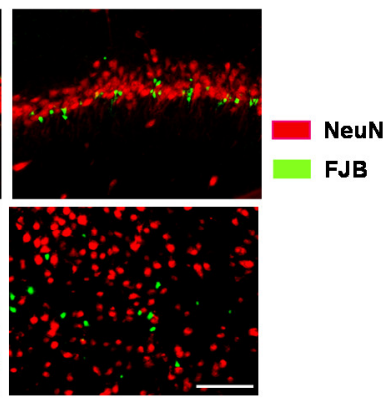

B.

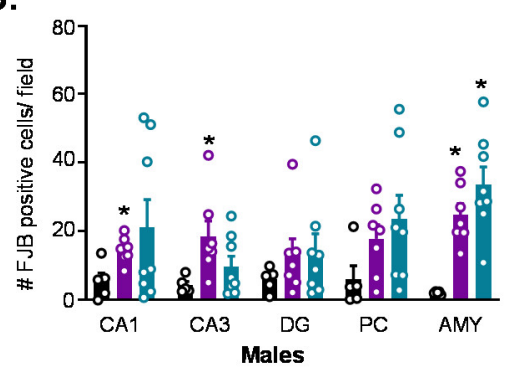

C.

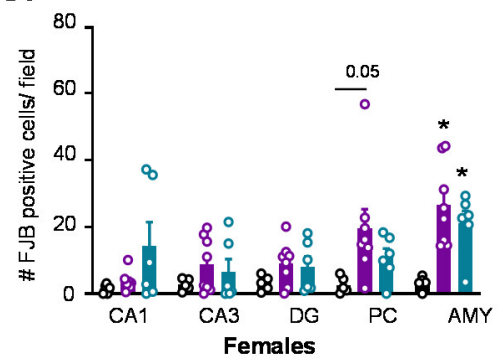

D.

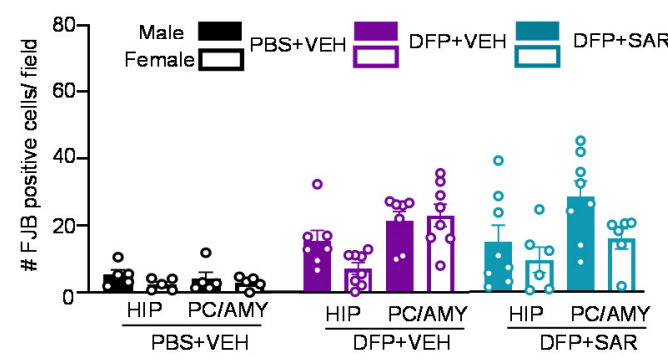

Figure 5. Neurodegeneration at day 8 post-DFP. (A) Representative IHC images for NeuN and FJB positive cells from each treatment group. Scale, $50 \mu \mathrm{m}$. (B,C) Number of FJB positive cells. (D) Averages were pooled from the hippocampus (CA1, CA3 and DG) as well as the PC and AMY to compare sex differences. For both, $n=5-8$, mixed measures ANOVA; ${ }^{*} p<0.05$ compared to controls and \# $p<0.05$ compared to DFP $+\operatorname{VEH}(\mathbf{B}, \mathbf{C}) .{ }^{*} p<0.05$ males vs females; $p$-values indicated numerically when $p<0.1$ (D). Field is $0.44 \mathrm{~m}^{2}$.

\subsubsection{Impact of DFP and SAR on Learning and Memory}

Animals were assessed for learning and memory in the novel object recognition test. A graphical representation of the test is illustrated in top panels in Figure 7A-D. On the first day of the test, there was no significant difference between any treatment groups in the amount of time animals spent in the center of the apparatus (Figure 7A). On the second day, we measured the time the animals spent exploring either object and found no difference between the treatment groups (Figure 7B). Three hours after familiarization, animals were placed into the apparatus with the familiar object and a novel object. DFP and VEH groups had 53\% lower (though not significant) discrimination indices compared to controls (treated with PBS) that were mitigated by SAR by $73 \%$, though the differences were not significant (Figure $7 \mathrm{C}$ ). Testing was again completed $24 \mathrm{~h}$ later with a different novel object to assess long-term memory. There were no significant differences between the groups, and discrimination indices were low for all groups (Figure 7D).

To further test learning and memory, animals were assessed by the MWM test. A graphical representation of the test is presented in Figure 7E. On the first day, animals were placed in the water with the platform visible at the center of the tank. Over four trials, all treatment groups found the platform faster; there was no significant difference between the groups (Figure 7F). On days 2-7, animals were tested for reaching a submerged platform in the water. There were no significant differences in the number of times animals took to find the submerged platform between any treatment groups (Figure 7G). Then, $24 \mathrm{~h}$ later, animals were placed in the tank for $60 \mathrm{~s}$ without the platform. All treatment groups spent more time in the target quadrant, though this was only significant for the DFP-and SAR-treated animals (Figure $7 \mathrm{H}$ ). A representative trial for each group is presented in Figure 7I. 
A.

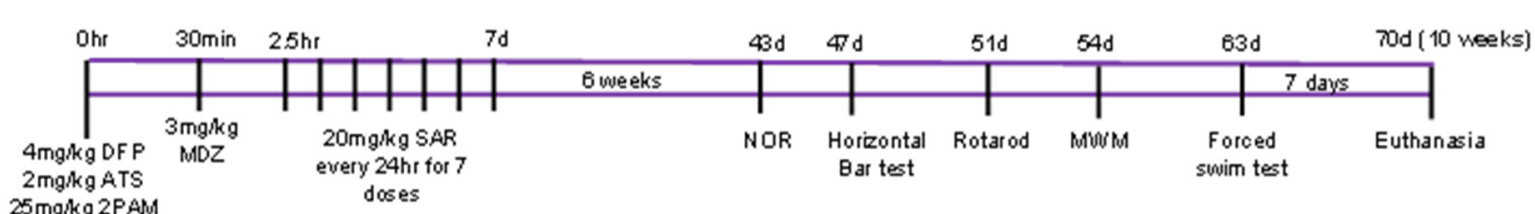

B.

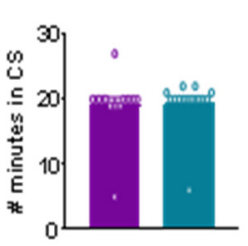

C.

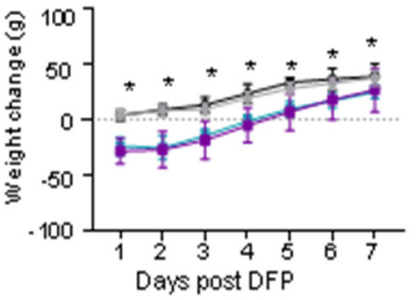

D.

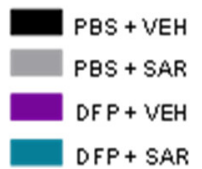

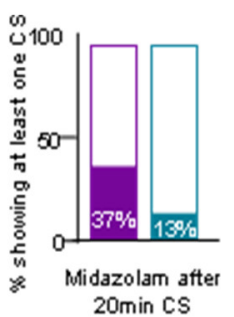

E.

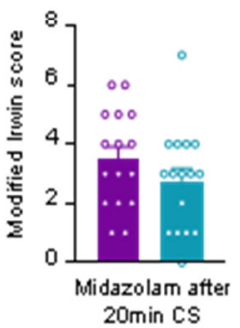

Figure 6. (A) Experimental design for long-term effects of DFP intoxication and mitigation by SAR (10 weeks post-DFP). Male rats were challenged with $4 \mathrm{mg} / \mathrm{kg}$ DFP followed by $2 \mathrm{mg} / \mathrm{kg}$ atropine sulfate (ATS) and $25 \mathrm{mg} / \mathrm{kg}$ pralidoxime (2-PAM). About 5-10 min post DFP, animals began to display convulsive seizures (CS). After $20 \mathrm{~min}$ of first CS midazolam (MDZ) was administered (i.e., 30 min post-DFP). Two hours after MDZ, animals were administered $20 \mathrm{mg} / \mathrm{kg}$ saracatinib (SAR) or vehicle (VEH) once a day for 7 days. Six weeks after DFP intoxication, animals were tested for behavioral comorbidities: novel object recognition (NOR), horizontal bar test, rotarod, Morris water maze (MWM), and forced swim test. (B-E) Seizure severity and morbidity measures during the treatment period for animals with $\sim 20 \mathrm{~min}$ SE. (B) There was no difference in the number of minutes animals spent in CS during SE between SAR and VEH treated animals ( $t$-test, $n=15-16$ ). (C) Bodyweight change over the treatment period for each treatment group ( $n=13-16$, mixed measures ANOVA). (D) $37 \%$ of VEH treated animals and $13 \%$ of SAR treated animals had at least one spontaneous convulsive seizure (CS) while handling during the treatment period (Fisher's exact). (E) Animals were assessed for morbidity measures using the modified Irwin scale $\left(n=15-16, t\right.$-test). ${ }^{*} p<0.05$.

\subsubsection{Impact of DFP and SAR on Anxiety, Depression and Motor Activity}

DFP-treated animals (both VEH and SAR) spent less time immobile and had fewer immobile episodes compared to the control groups, though this was not significant (Figure 8A,B). On the rotarod, a measure of motor coordination, there were no differences between days one and two of training or between groups for the latency to fall (Figure 8C). On the horizontal bar test, we did not see any differences in the number of foot slips on any of the bars between the groups (Figure 8F,I,L). We did, however, see differences in how fast animals crossed the beam, which may indicate anxiety or impulsivity indirectly (see Discussion). All groups reached the goal-box significantly faster on the second day of training $(4 \mathrm{~cm}$ beam) and required fewer pushes compared to the first day of training (Figure 8D,E). Interestingly, the PBS and VEH, DFP and VEH, and DFP and SAR all had fewer footslips on the second day compared to the first day (Figure 8F). After training, animals were then tested the next day using a $2 \mathrm{~cm}$ bar. Interestingly, DFP and VEH animals reached the goal significantly faster than PBS and SAR animals (Figure 8G), and there were no differences in the number of foot slips between groups in both $2 \mathrm{~cm}$ and $1 \mathrm{~cm}$ bars (Figure 8I,L). DFP and SAR animals took more time to reach the goal, but this was not significant. The same trends, as with the $2 \mathrm{~cm}$ bar, were observed for the number of pushes animals required to walk across the beam (Figure $8 \mathrm{G}$ ). When animals were tested on the $1 \mathrm{~cm}$ beam, there were no significant differences between the groups for both the time it took animals to reach the goal and the number of pushes that were required (Figure $8 \mathrm{H}, \mathrm{I}$ ). 

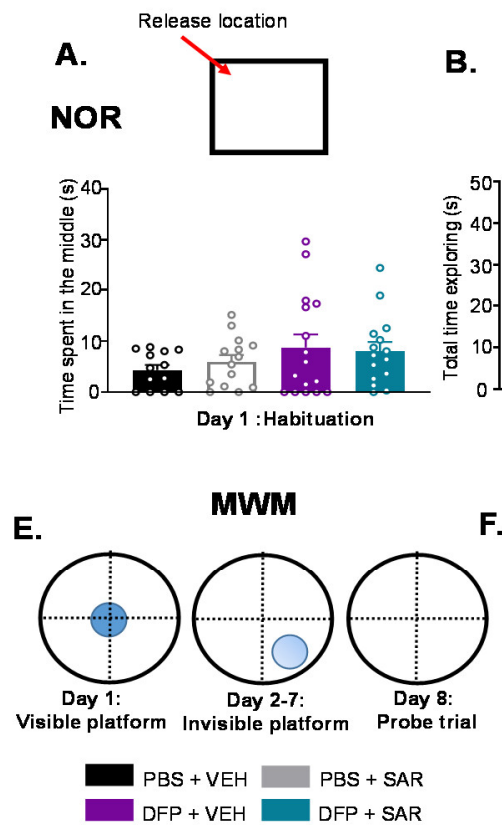

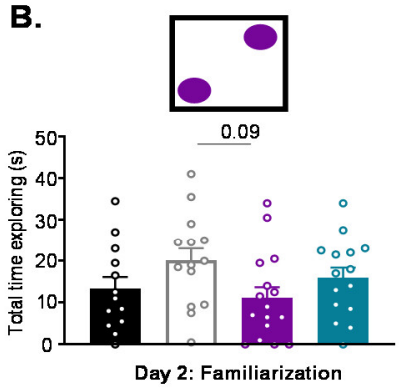

$\mathbf{F}$

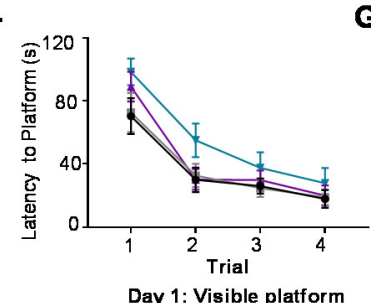

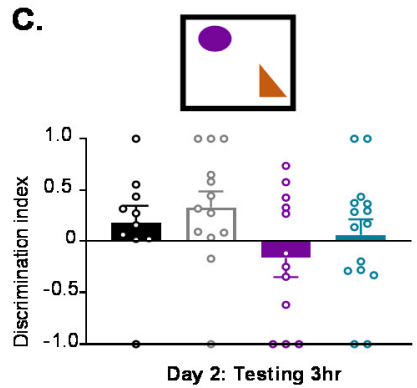

Day 2: Testing 3hr
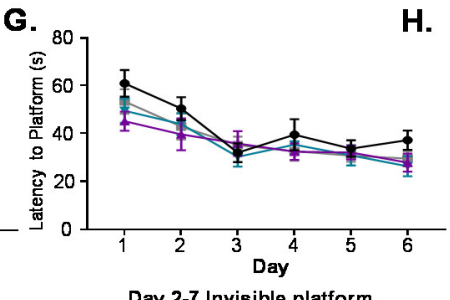

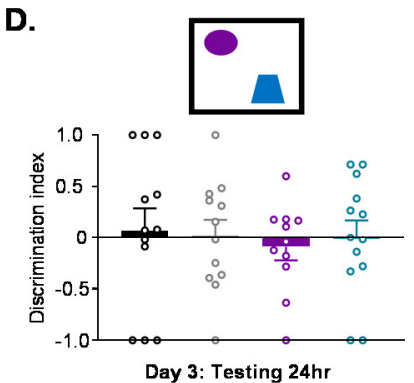

I.
H.

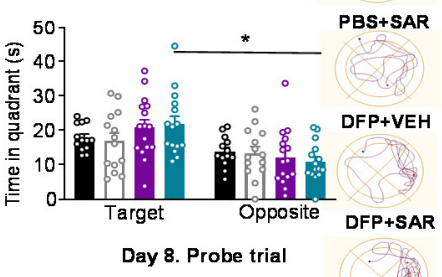

Figure 7. Effects of DFP and SAR or VEH on learning and memory in the novel object recognition test (NOR) and Morris water maze (MWM). (A-D) Experimental design for the NOR is illustrated in boxes. (A) On the first day (habituation) animals were allowed to explore the empty apparatus, a large square arena $\left(100 \mathrm{~cm}^{2}\right)$. Amount of time spent in the center of the apparatus for each treatment group is presented. (B) On the next day (familiarization), animals were placed into the same apparatus with two identical objects; amount of time animals spent exploring the objects is presented. (C) Three hours later, one of the objects was replaced with a novel object. (D) $24 \mathrm{~h}$ post-familiarization, a new novel object replaced the previously used novel object. Higher discrimination indices indicate a greater proportion of time spent with the novel object. (E) Experimental design for the MWM. The apparatus consisted of a large tank $(60 \mathrm{~cm}$ high, $180 \mathrm{~cm}$ diameter) filled with water; several visually distinct cues lined the tank. On the first day, a visible platform was placed in the center of the tank; animals were trained to reach the platform. On days 2-7, animals were trained (4 trials a day) to find an invisible platform using the cues. On the 8th day, animals were released into the tank without a platform and time spent in the target quadrant (prior platform location) was measured (probe trial). (F) Time to the visible platform for four trials during the first day of training. (G) Time to the invisible platform on days 2-7 of training. (H) Time spent in the target and opposite quadrant during the probe trial. (I) Representative trial plots from each group. All, $n=13-16$, ANOVA, or mixed measures ANOVA. ${ }^{*} p<0.05 ; p$-values indicated numerically when $p<0.1$.

\subsection{Long Term Impact of DFP and Mitigation by SAR on Gliosis and Neurodegeneration in} Animals with 20 min of Continuous CS during SE

Following behavioral tests, animals were given 3-4 days of rest (about 10 weeks after DFP intoxication) and then were euthanized to assess gliosis and neurodegeneration, as in the previous cohort of mixed-sex. One-half of the animals were perfuse-fixed with $4 \%$ PFA for IHC, while the other half of the animals were used for Western blotting without perfusion.

\subsubsection{Microgliosis}

Representative IHC images of IBA1 and CD68 staining are shown in Figure 9A. Interestingly, in the hippocampus of the DFP and VEH group, there were no differences between the groups for the total number of IBA1 positive cells (Figure 9B), percent of IBA1 positive cells with CD68 (Figure 9C), or the number of IBA1 positive cells with reactive morphology (Figure 9D). However, we found a significant increase in all of these parameters for DFPand VEH-treated animals in the PC and the AMY (Figure 9B-D). SAR treatment led to 
a reduction of IBA1 positive cells compared to DFP- and VEH-treated animals in the PC (significant) and AMY (not significant) (Figure 9B). Similarly, there was also a reduction in IBA1 cells with reactive morphology in DFP and SAR animals compared to DFP and VEH animals in the PC (significant) and AMY (not significant) (Figure 9D). DFP- and SAR-treated animals also had a reduction in the percent of CD68 positive cells compared to DFP and VEH in the PC and AMY, but the reduction was not statistically significant (Figure 9C).

A.
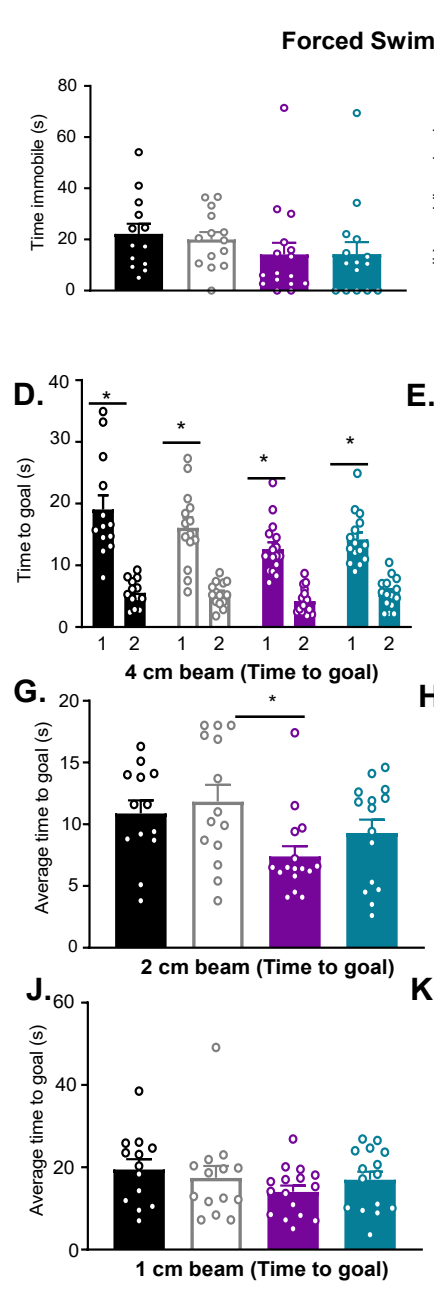

B.

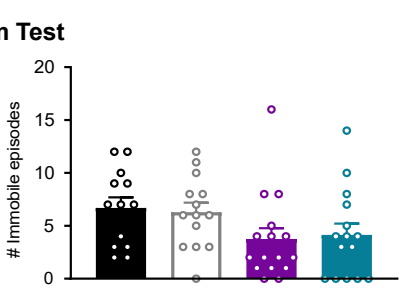

C.

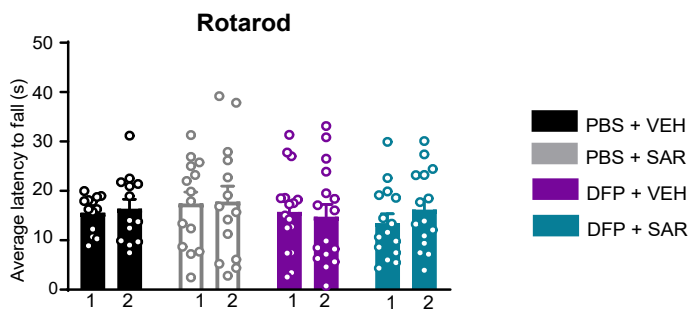

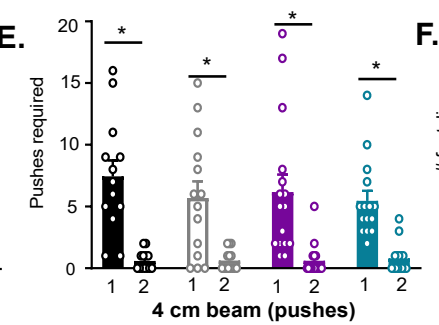
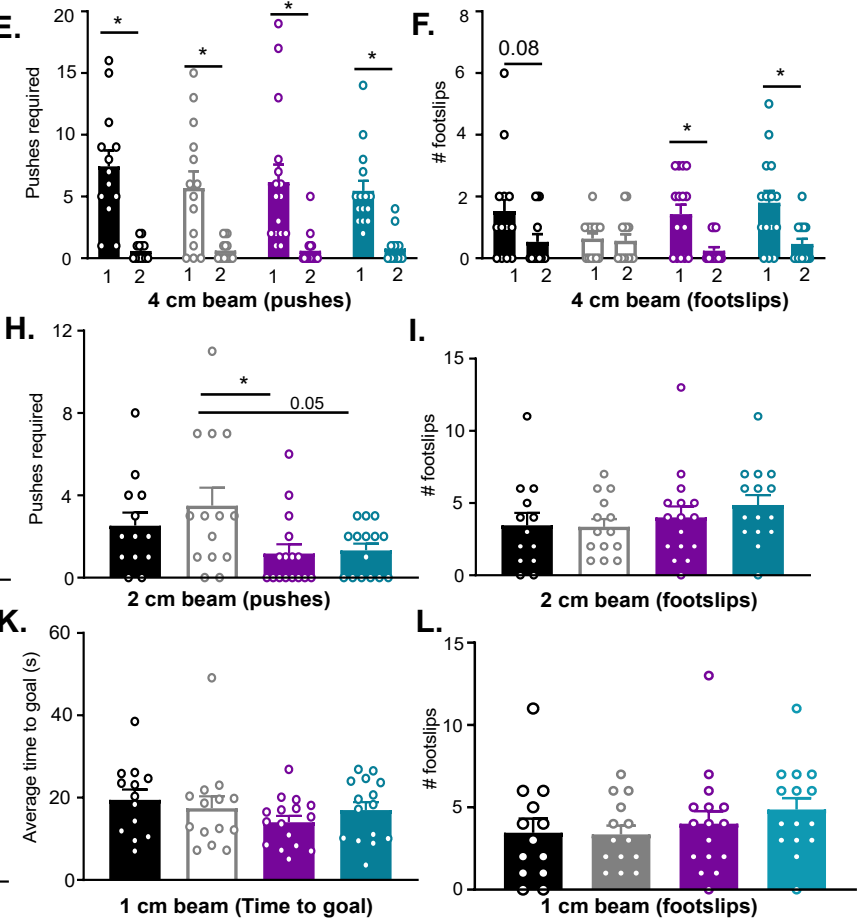

Figure 8. Effects of DFP and SAR or vehicle on depression (forced swim test), anxiety (forced swim test and horizontal bar tests), and motor coordination (horizontal bar test and rotarod). (A,B) Immobility time (A) and number of immobile episodes (B) in the forced swim test. (C) Latency to fall on the rotarod for two days of training is plotted. The numbers $(1,2)$ represent days of testing. (D-L) The horizontal bar tests. $(\mathbf{D}, \mathbf{G}, \mathbf{J})$ Time to the safety box, $(\mathbf{E}, \mathbf{H}, \mathbf{K})$ and number of pushes required, and $(\mathbf{F}, \mathbf{I}, \mathbf{L})$ the number of foot slips on the first two days of training and $24 \mathrm{~h}$ after training on $4 \mathrm{~cm}, 2 \mathrm{~cm}$, and $1 \mathrm{~cm}$ bars. All, $n=13-16$, ANOVA or mixed measures ANOVA. ${ }^{*} p<0.05 ; p$-values indicated numerically when $p<0.1$.

\subsubsection{Astrogliosis}

Representative images from the hippocampus and AMY for GFAP are shown in Figure 10A. There was no difference in the number of GFAP positive cells between groups (Figure 10B). There was only a significant difference in the number of GFAP positive cells with reactive morphology in the AMY and PC but not in the hippocampus (Figure 10C). 
There was significant mitigation by SAR of DFP-induced change in GFAP morphology in both the AMY and PC (Figure 10C).
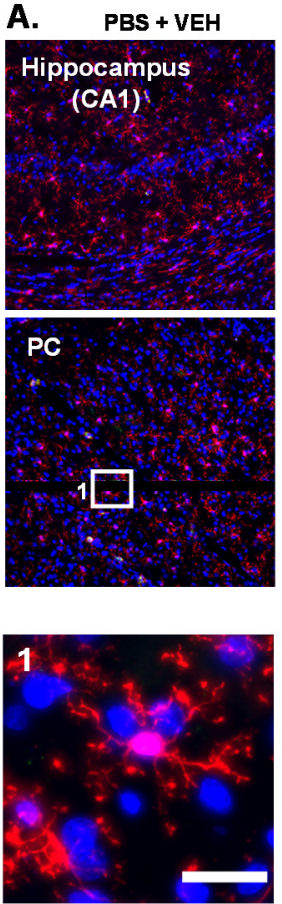

PBS + SAR
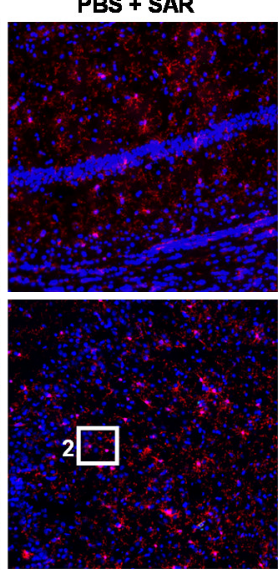

IBA1

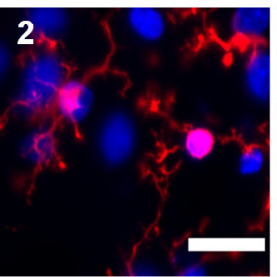

DFP + VEH
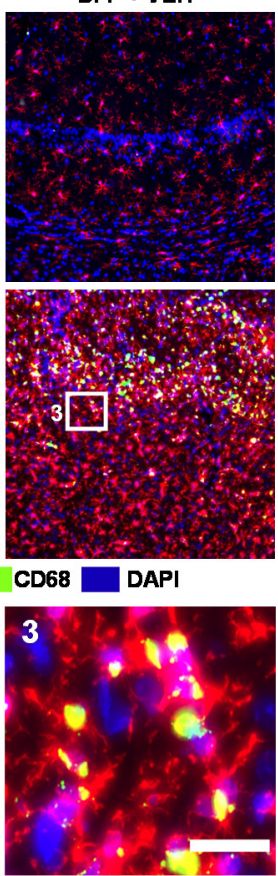

DFP + SAR
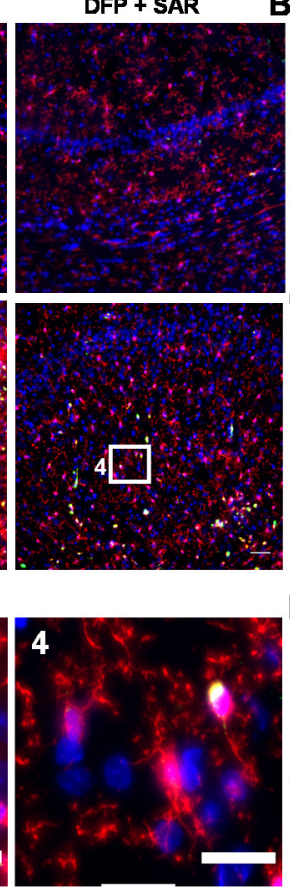

B.

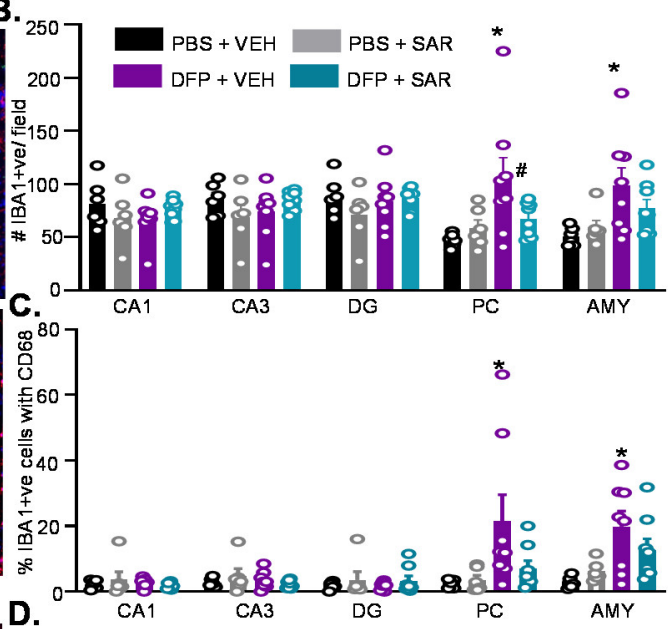

D.

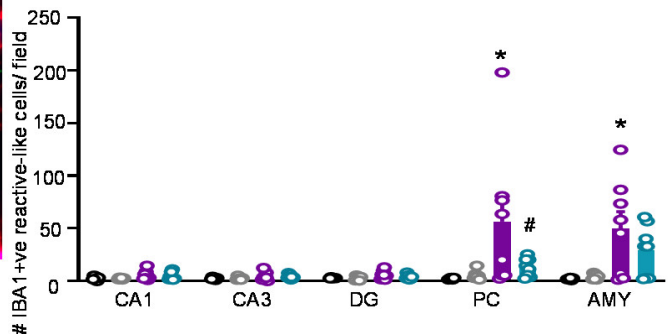

Figure 9. Microgliosis 10 weeks post-DFP ( $20 \mathrm{~min}$ of SE) and mitigation by SAR. (A) Representative IHC images of IBA1 and CD68 positive cells from each treatment group. Scale, $50 \mu \mathrm{m}$ for whole field $\left(0.44 \mathrm{~m}^{2}\right)$ images and $25 \mu \mathrm{m}$ for boxed images (1-4). (B-D) Cell quantification. (B) Number of IBA1 positive cells. (C) Percent IBA1 positive cells colocalized with CD68 positive cells. (D) Number of IBA1 positive cells with reactive-type morphology. Reactive cells were considered to have large cell bodies and retracted processes. All, $n=6-8$, mixed measures ANOVA. ${ }^{*} p<0.05$ compared to at least one control group \# $p<0.05$ compared to DFP + VEH (B-G).

\subsubsection{Neurodegeneration}

We further analyzed the number of FJB positive cells; representative images are shown in Figure 11A. In DFP and VEH animals, there was a significant upregulation of FJB positive cells in the PC and AMY, but not in the hippocampus, compared to controls (Figure 11B). This was significantly mitigated by SAR treatment.

\subsection{SAR Mitigates DFP-Induced Toxicity as an Antioxidant}

Considering the significant mitigation of neurodegeneration and reactive gliosis by SAR, we hypothesized that SAR could target nitroxidative stressors to achieve its neuroprotective role as an antioxidant. We utilized IHC and Western blotting to determine the expression levels of inducible nitric oxide synthase (iNOS), 3-nitrotyrosine (3NT) and GP91 ${ }^{\text {phox }}$ (a subunit of NADPH oxidase). We hypothesized that the number of positive iNOS, 3NT, and GP91 ${ }^{\text {phox }}$ cells might be associated with glial activation. Therefore, we used a simple linear regression to determine the correlation between the markers of oxidative stress and the number of reactive microglia and astrocytes in each treatment group. These regressions are outlined in Tables S2-S4. 

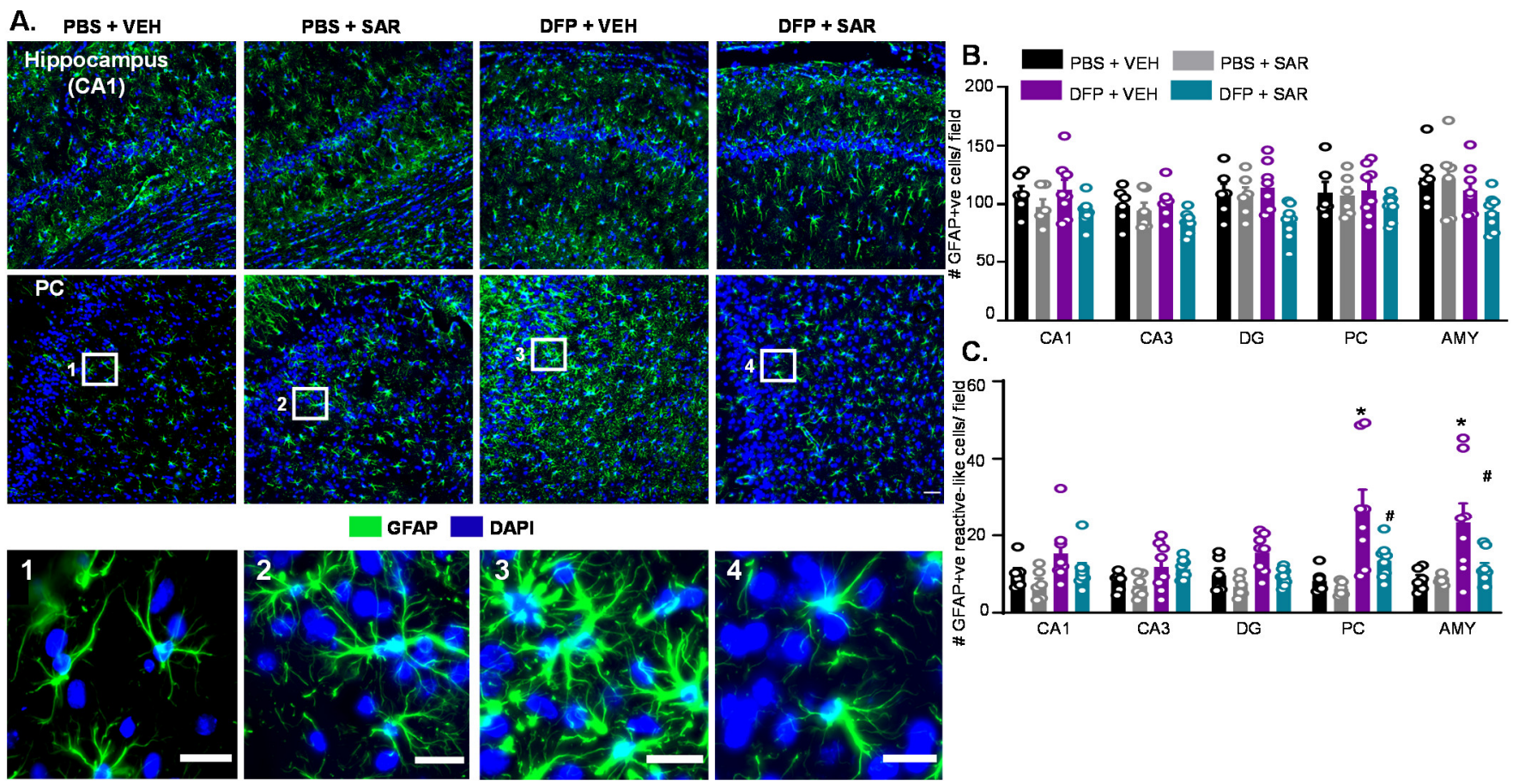

Figure 10. Astrogliosis 10 weeks post-DFP ( 20 min of SE) and mitigation by SAR. (A) Representative IHC images of GFAP positive cells from each treatment group. Scale, $50 \mu \mathrm{m}$ for whole field $\left(0.44 \mathrm{~m}^{2}\right)$ images and $25 \mu \mathrm{m}$ for boxed images (1-4). (B,C) Cell quantification. (B) Number of GFAP positive cells. (C) Number of GFAP positive cells with reactive-type morphology. Reactive cells were considered to have large cell bodies and retracted processes. All, $n=6-8$, mixed measures ANOVA. * $p<0.05$ compared to at least one control group \# $p<0.05$ compared to DFP + VEH (B-G).

\subsubsection{SAR Mitigates DFP-Induced iNOS}

Representative images of iNOS for each treatment group are shown in Figure 12A. iNOS was primarily localized in microglia (IBA1 positive cells); we therefore only counted iNOS positive cells that were colocalized with IBA1. There was a significant upregulation of iNOS in DFP- and VEH-treated animals in the AMY with significant mitigation by SAR (Figure 12B). There was also upregulation of iNOS in the PC, but this was not significant. We hypothesized that the degree of iNOS positive cells might be indicative of the degree of glial activation. A simple linear regression showed a significant correlation between the number of IBA1 positive cells with reactive morphology and the number of iNOS positive cells in the DFP and VEH group, but not the other groups (Figure 12C, PC, $\mathrm{R}^{2}=0.577$, AMY $R^{2}=0.660$ ). There was also a significant correlation between the number of iNOS positive cells and GFAP positive cells with reactive morphology in the PC of the DFP and SAR group (Figure 12D, $R^{2}=0.737$ ).

\subsubsection{SAR Mitigates DFP-Induced 3NT}

Representative IHC images of 3NT for each treatment group are shown in Figure 13A. There was little-to-no staining in control animals and DFP and SAR animals. There was upregulation of 3NT in the DFP and VEH in both the PC and AMY (Figure 13B). In the PC, SAR significantly mitigated DFP-induced upregulation of 3NT (Figure 13B). Following a simple linear regression analysis, we found a significant correlation between the number of 3NT positive cells and the number of reactive type IBA1 positive cells for the DFP and VEH group in both the PC $\left(R^{2}=0.784\right)$ and AMY $\left(R^{2}=0.541\right)$ (Figure 13C). This was similar for the DFP and SAR group in the PC $\left(R^{2}=0.856\right)$ and AMY $\left(R^{2}=0.825\right)$ (Figure 13D). Interestingly, there was no significant correlation for any group in any location between the number of 3NT positive cells and reactive type GFAP positive cells. There were no 
significant changes in the expression of 3NT in the PC / AMY region, as revealed by Western blotting (Figure S2A,B).

A.
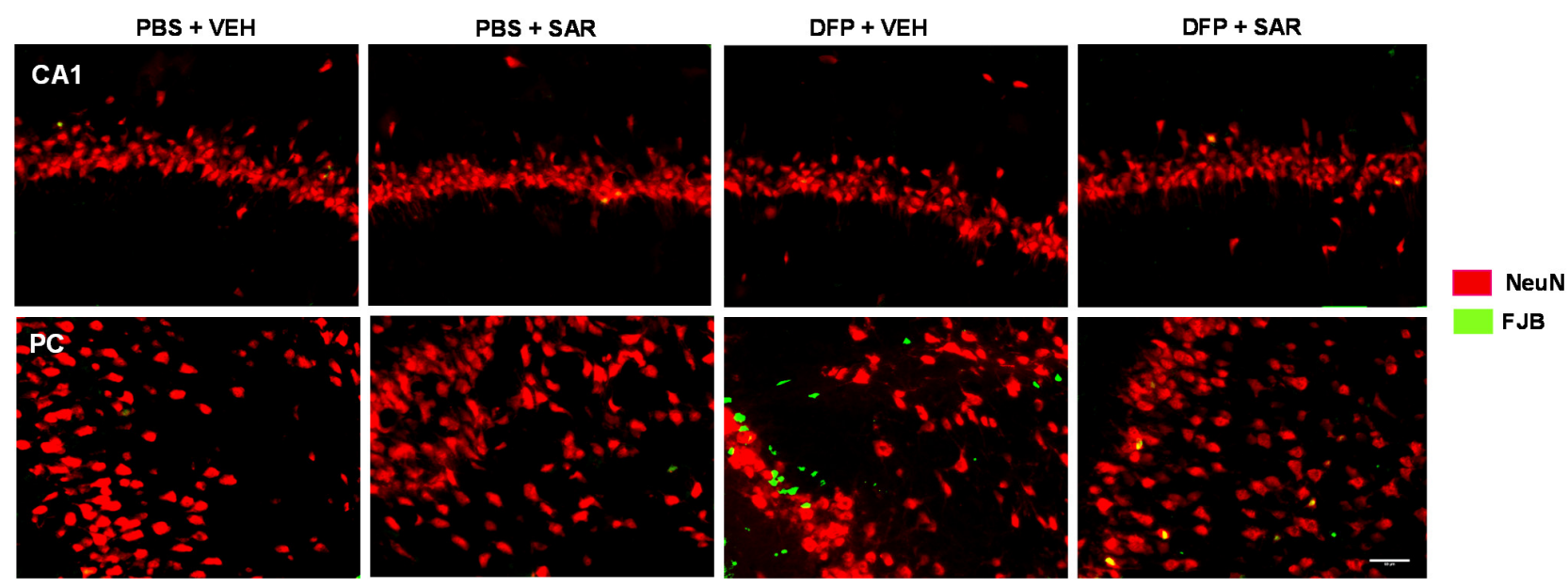

B.

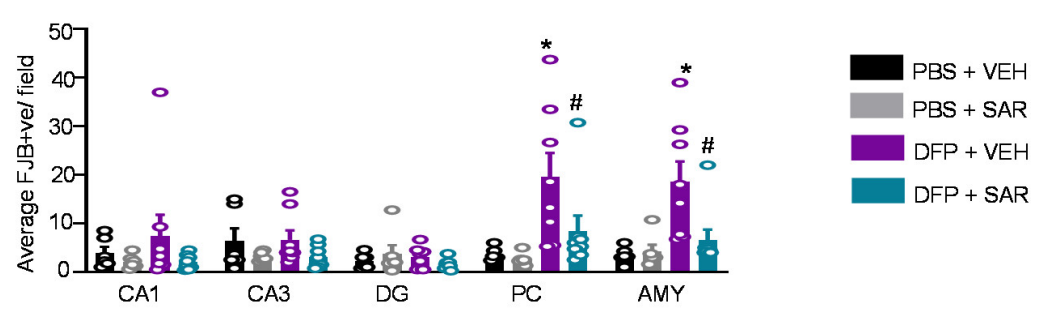

Figure 11. Neurodegeneration 10 weeks post-DFP ( $20 \mathrm{~min}$ of SE) and mitigation by SAR. (A) Representative IHC images for NeuN and FJB positive cells from each treatment group. Scale, $50 \mu \mathrm{m}$. (B) Number of FJB positive cells $(n=6-8$, mixed measures ANOVA* $p<0.05$ or $p$-values indicated numerically when $p<0.1$ compared to at least one control group, \# $p<0.05$ compared to DFP + VEH (B-G). Field is $0.44 \mathrm{~m}^{2}$.

\subsubsection{Impact of DFP and SAR on GP91 phox}

Representative IHC images of GP91 ${ }^{\text {phox }}$ are shown in Figure 14A. Many of the GP91 ${ }^{\text {phox }}$ cells colocalized with IBA1 positive cells in the PC and AMY; we, therefore, counted GP91 phox positive cells that were colocalized with IBA1. There was a nonsignificant upregulation of GP91 ${ }^{\text {phox }}$ positive cells in DFP and VEH animals compared to controls with mitigation by SAR, though the difference was not significant (Figure 14B). Following simple linear regression, we found a correlation between GP91 ${ }^{\text {phox }}$ positive cells and IBA1 positive cells with reactive type morphology in the AMY of DFP- and SAR-treated animals but not any other group or location (Figure 14C). There were no significant correlations between the number of GP91 ${ }^{\text {phox }}$ positive cells and the number of GFAP positive cells with reactive type morphology (Figure 14D). There was no difference in GP91 ${ }^{\text {hox }}$ in the PC/AMY region between the treatment groups as revealed by Western blotting (Figure S2C,D). 

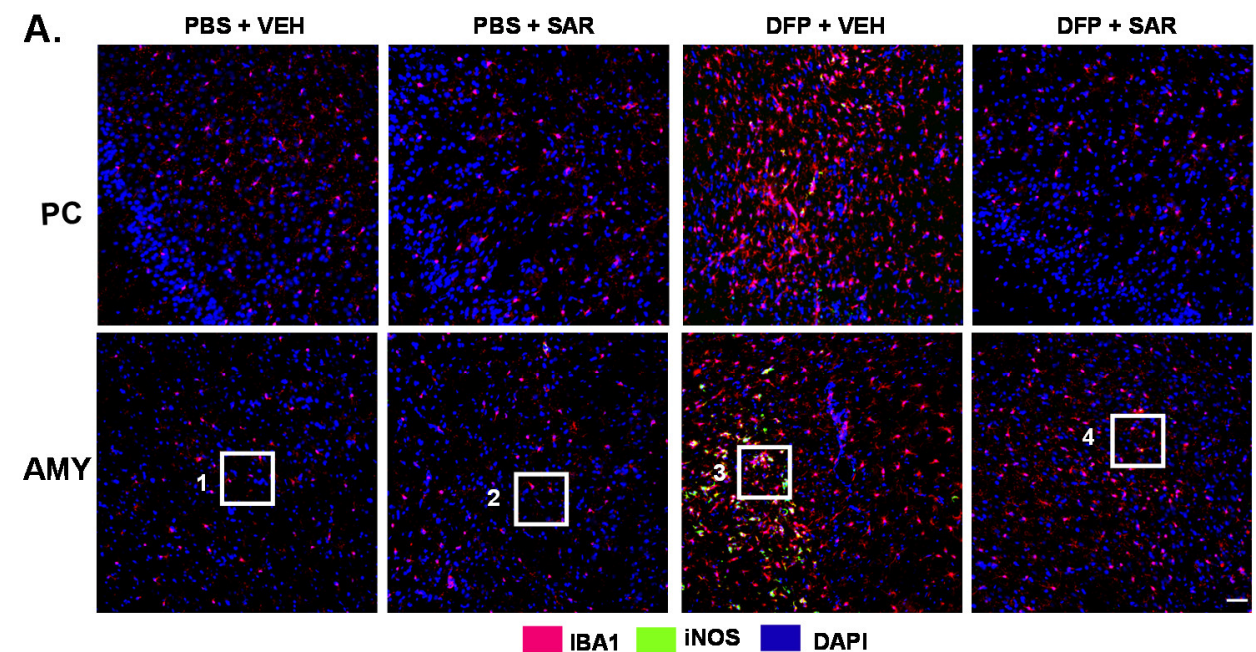

B.
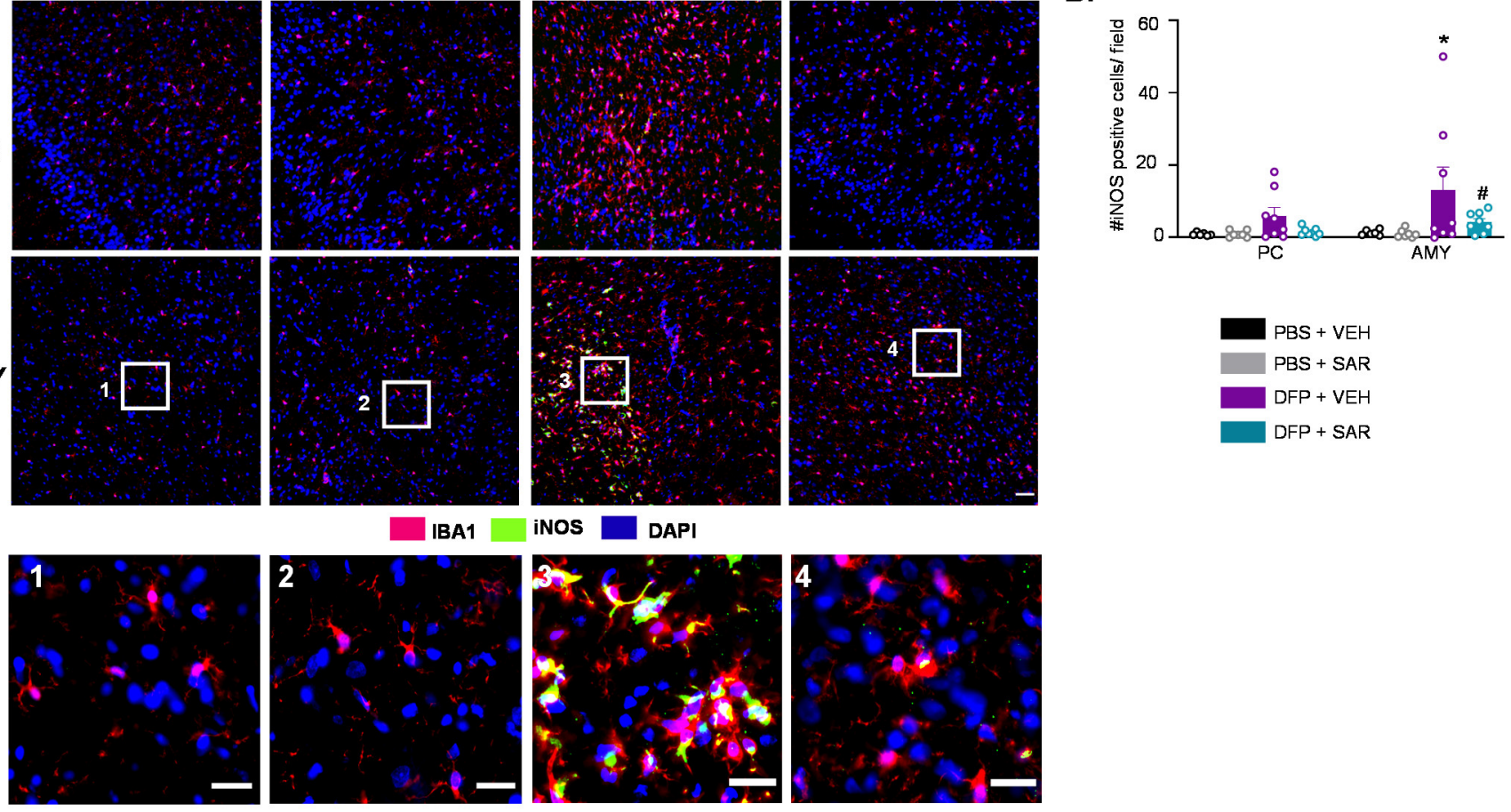

C.
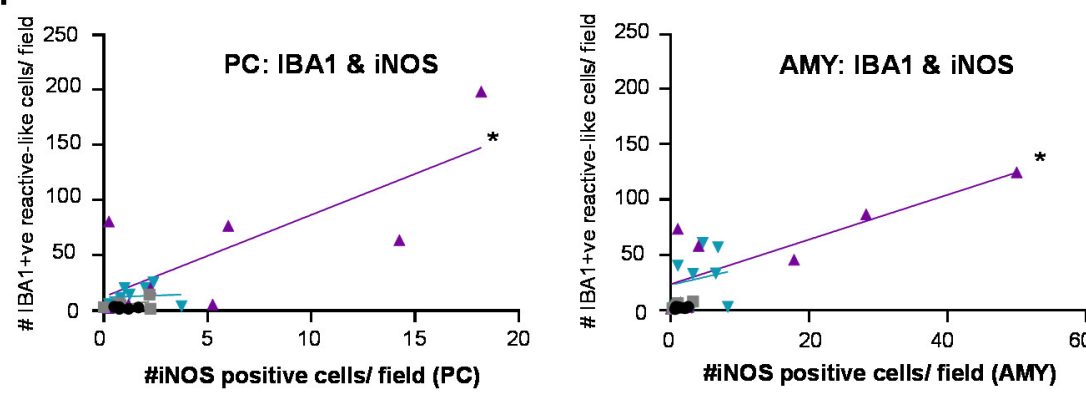

D.
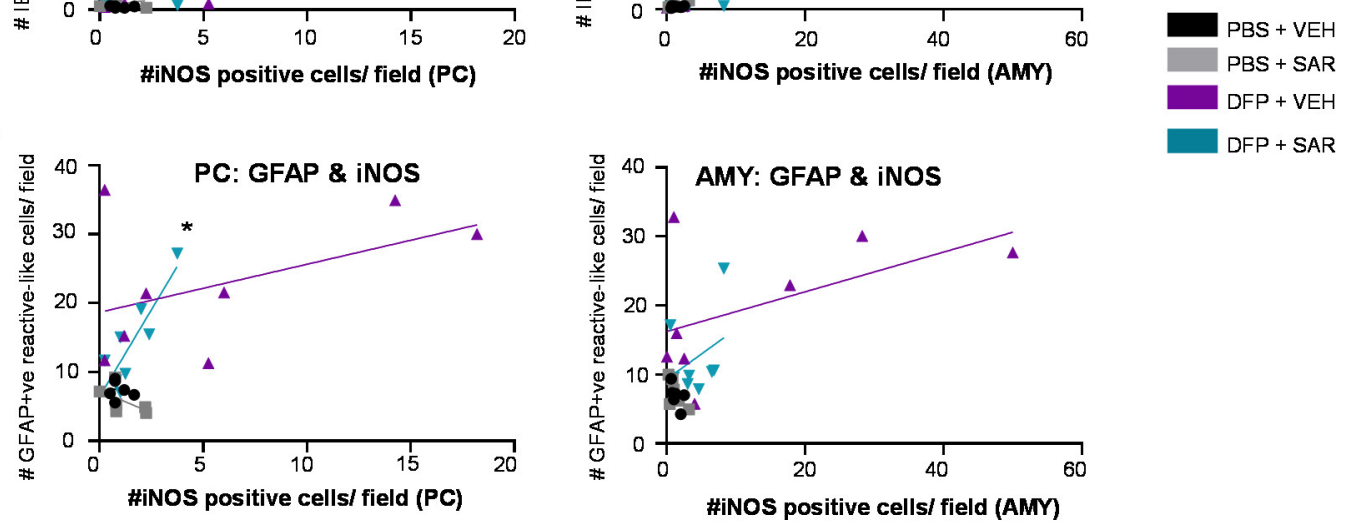

Figure 12. iNOS expression 10 weeks post-DFP ( 20 min of SE) and mitigation by SAR. (A) Representative IHC images of iNOS and IBA1 positive cells from each treatment group. Scale, $50 \mu \mathrm{m}$ for whole field $\left(0.44 \mathrm{~m}^{2}\right)$ images and $25 \mu \mathrm{m}$ for boxed images (1-4). (B) Number of iNOS positive cells ( $n=6-8$, mixed measures ANOVA). (C) Number (\#) of iNOS positive cells compared to the number of IBA1 positive cells with reactive type morphology ( $n=6-8$, simple linear regression). (D) Number of iNOS positive cells compared to the number of GFAP positive cells with reactive type morphology ( $n=6-8$, simple linear regression). ${ }^{*} p<0.05$ compared to at least one control group or a positive correlation, \# $p<0.05$ compared to DFP + VEH (B-G). 

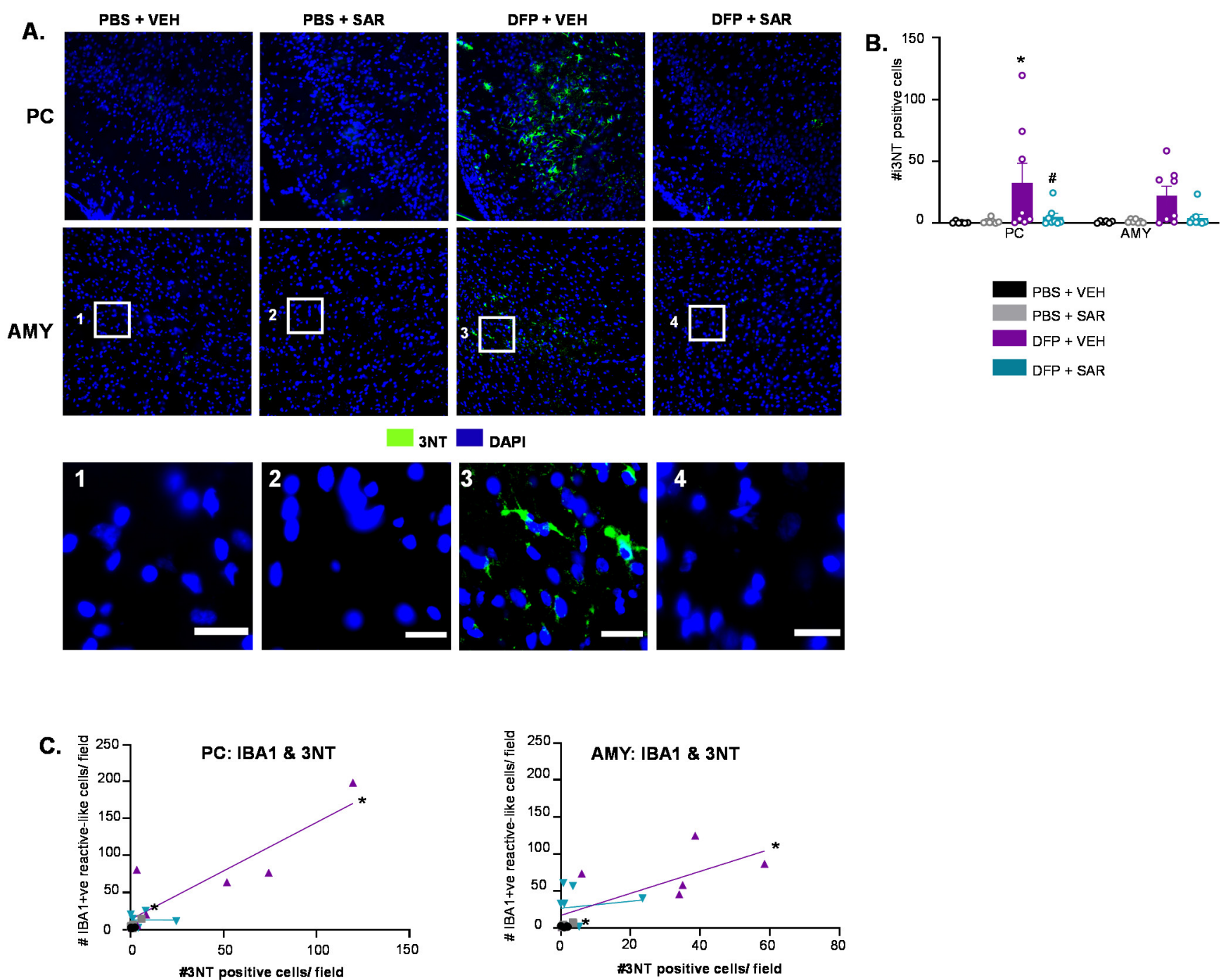

D.
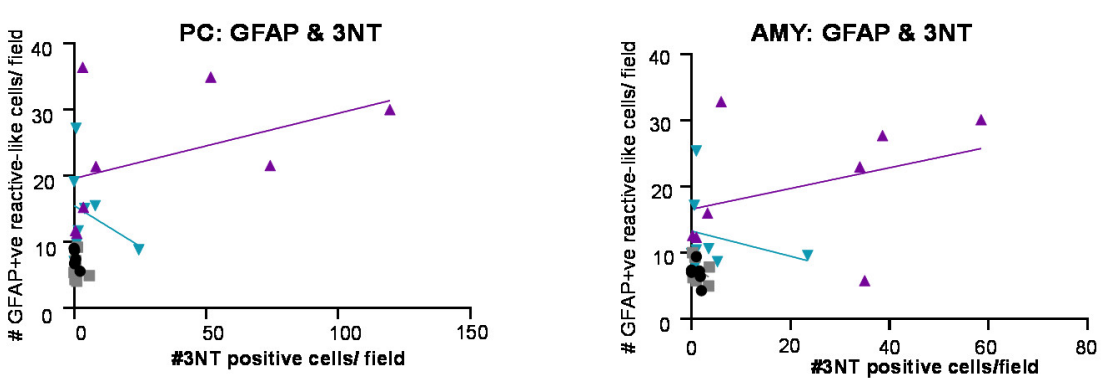

Figure 13. 3NT expression 10 weeks post-DFP ( 20 min of SE) and mitigation by SAR. (A) Representative IHC images of 3NT positive cells from each treatment group. Scale, $50 \mu \mathrm{m}$ for whole field $\left(0.44 \mathrm{~m}^{2}\right)$ images and $25 \mu \mathrm{m}$ for boxed images (1-4). (B) Number (\#) of 3NT positive cells ( $n=6-8$, mixed measures ANOVA). (C) Number of 3NT positive cells compared to the number of IBA1 positive cells with reactive type morphology ( $n=6-8$, simple linear regression). (D) Number of 3NT positive cells compared to the number of GFAP positive cells with reactive type morphology ( $n=6-8$, simple linear regression). ${ }^{*} p<0.05$ compared to PBS $+\mathrm{VEH}$ and $\# p<0.05$ compared to $\mathrm{DFP}+\mathrm{VEH}(\mathbf{B}){ }^{*} p<0.05$ significant correlation $(\mathbf{C}, \mathbf{D})$. 

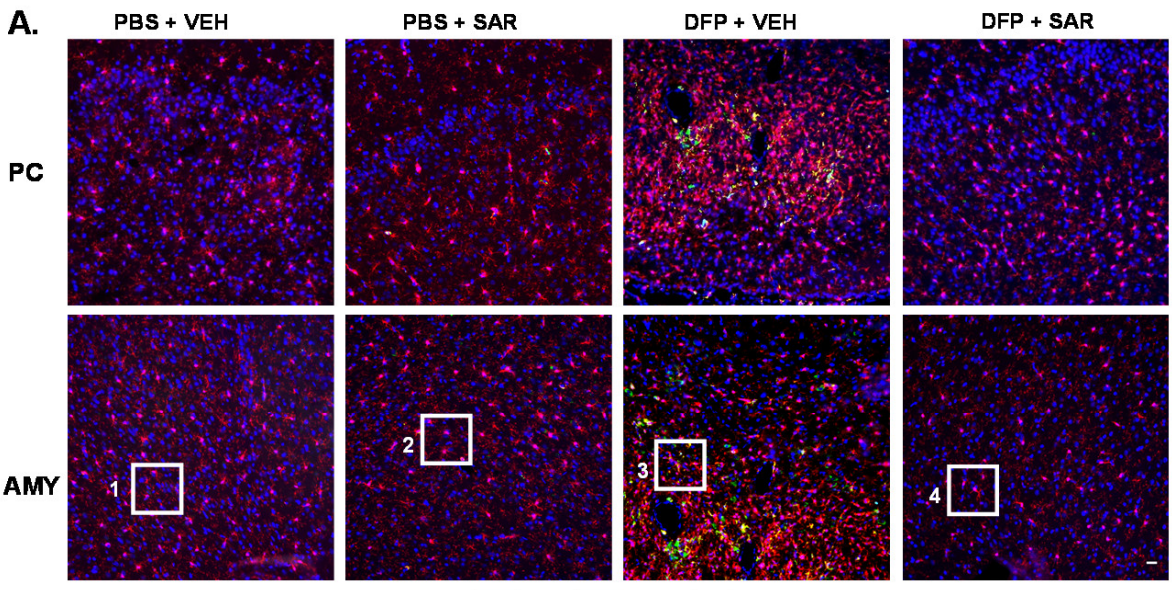

IBA1 GP91 DAPI
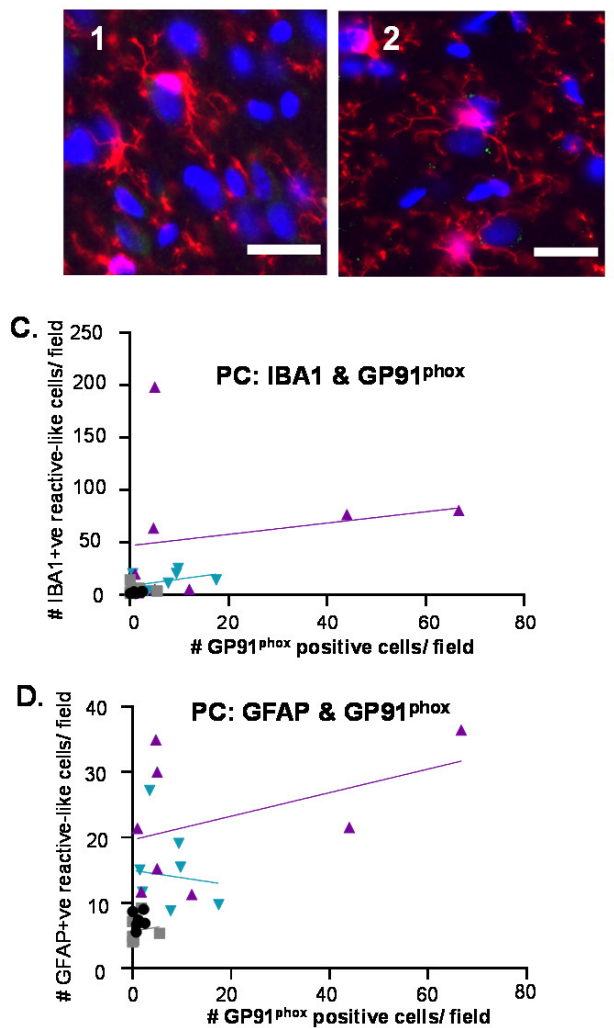
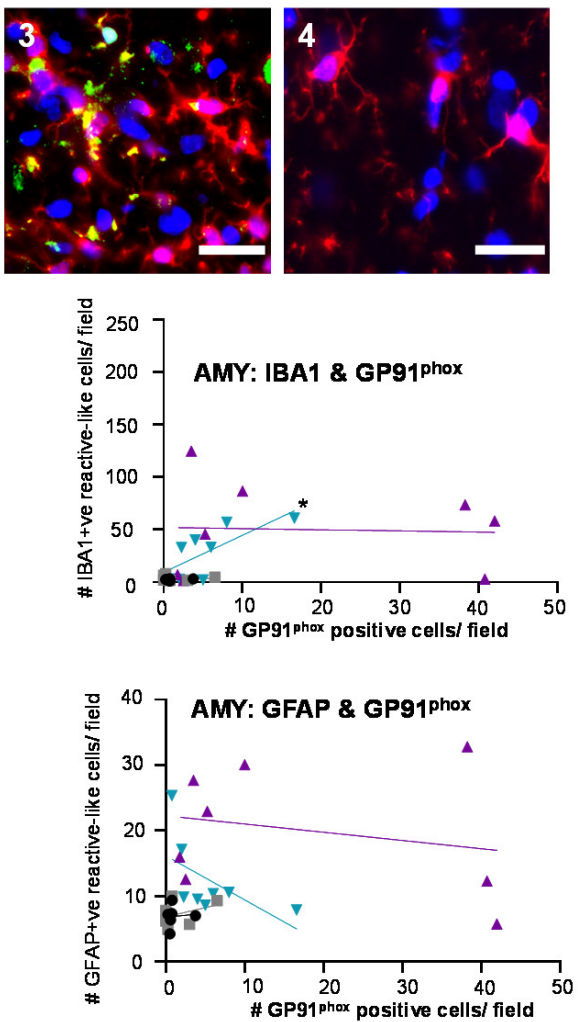
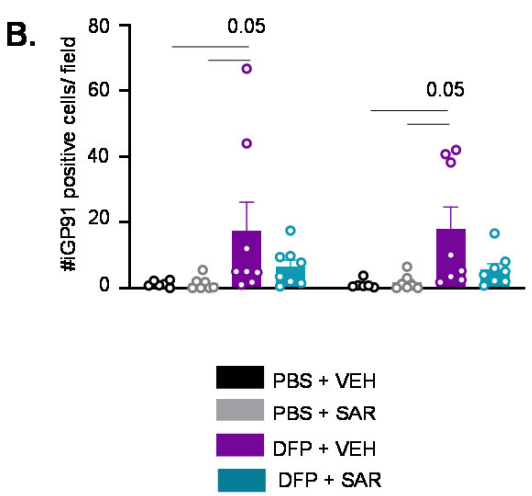

Figure 14. GP91 ${ }^{\text {phox }}$ expression 10 weeks post-DFP ( 20 min of SE) and mitigation by SAR. (A) Representative IHC images of GP91 ${ }^{\text {phox }}$ positive cells from each treatment group. Scale, $50 \mu \mathrm{m}$ for whole field $\left(0.44 \mathrm{~m}^{2}\right)$ images and $25 \mu \mathrm{m}$ for boxed images (1-4). (B) Number (\#) of GP91 ${ }^{\text {phox }}$ positive cells ( $n=6-8$, mixed measures ANOVA). (C) Number of GP91 ${ }^{\text {phox }}$ positive cells compared to the number of IBA1 positive cells with reactive type morphology ( $n=6-8$, simple linear regression). (D) Number of GP91 $1^{\text {phox }}$ positive cells compared to the number of GFAP positive cells with reactive type morphology ( $n=6-8$, simple linear regression; $p$-values indicated numerically when $p<0.1)$.

\section{Discussion}

The purpose of this study was to determine the disease-modifying potential of SAR in an OP model of epilepsy in both males and females. SAR is a potent inhibitor of SFKs, which include Src, Yes, Trk, Fgr, Hck, Blk, Lck, Lyn, and Fyn. SAR has an IC50 of $2.7 \mathrm{nM}$ and $10 \mathrm{nM}$ against c-Src and Fyn, respectively, when tested in vitro [83]. SAR and other SFK inhibitors were first used in cancer models and have been found to be well tolerated in patients with solid tumors; $175 \mathrm{mg}$ once daily was found to be the maximum 
tolerable dose $[84,85]$. Notably, we used $20 \mathrm{mg} / \mathrm{kg}$ once daily, which is equivalent to about $195 \mathrm{mg}$ for the average-weight human. Human studies have shown some adverse effects to SAR administration, such as fatigue, nausea, diarrhea, and headaches $[67,86]$. Notably, we did not observe any side effects in this study with $20 \mathrm{mg} / \mathrm{kg}$ daily dose, unlike our previous study (using $25 \mathrm{mg} / \mathrm{kg}$ twice a day for the first three days) in the DFP model, where SAR-treated animals had increased weight loss and mortality compared to VEHtreated animals [70]. Although SAR treatment did not significantly mitigate weight loss or morbidity measures (Irwin analysis), it appears that $20 \mathrm{mg} / \mathrm{kg}$ is more tolerable in these animals. The mortality in the SAR group could be due to off-target effects from the early doses of SAR's reactive metabolites as discussed in our previous publication [70]. For example, some studies in the rat and human livers detected oxidative metabolites after exposure to SAR [87,88]. SAR is also bio-activated by P450 3A4 [87]. Interestingly, P430 3A4 is also required for the metabolism of MDZ, which was administered two hours prior to MDZ [89]. Since we have been dosing SAR orally at $20 \mathrm{mg} / \mathrm{kg}$ as a single dose/day, it is likely that rapidly accumulated SAR metabolites in the liver from the first 2-3 doses combined with DFP-induced gastrointestinal changes may have contributed to mortality in some animals [90]. Diet incorporation of SAR may achieve therapeutic concentrations of SAR gradually and could mitigate/minimize toxicity that normally occurs due to the rapid rise of SAR's metabolites in the liver. Alternatively, starting with a low dose in the first few days post-DFP followed by a dose-ramping approach could be beneficial.

SFK inhibition has been tested in a variety of animal models of neurological diseases. Importantly, our previous work and others' have demonstrated SAR's ability to cross the BBB in rodents $[57,91]$. SAR is also an inhibitor of the ATP-binding cassette transporter, ABCG2, which facilitates SAR to cross the BBB compared to the other SFK inhibitors [92,93]. For example, one study administered SAR in mice with the genetic background of AD and found that SAR mitigated deficits on the MWM when SAR treatment was prolonged for 3-5 weeks in contrast to a shorter treatment course (1-2 weeks) [91]. Similar results were shown in both the MWM and novel object test even when treatment was stopped eight days prior to testing [94]. A recent study used a new PET tracer ( $\left.{ }^{11} \mathrm{C}-\mathrm{UCB}-\mathrm{J}-\mathrm{PET}\right)$ in wild-type and AD mice and found that SAR treatment mitigated the loss in synaptic density [95]. There is also evidence for the beneficial effects of SFK inhibition in PD. In $\alpha$-synuclein PD model, SAR administration eight weeks after disease initiation attenuated the propagation of the $\alpha$-synuclein fibrils [96].

SAR has been tested in various clinical trials, including for breast cancer [86], prostate cancer [97], osteosarcoma, [98] and several others. Following its testing in cancer, SAR has also been tried in several models (both animal and human) of neurological diseases. One study administered 50-125 mg daily for four weeks to patients with probable AD and assessed tolerability as well as cognitive measures, via previously established scales [67]. There was no significant effect by SAR on any measure. Another study, using patients with mild AD dementia, administered 100-125 mg daily for a year [99]. Again, no significant improvement was observed for any clinical measure. The discrepancy between the success in animal models versus the lack of efficacy in clinical trials may be attributed to the level of disease progression and severity or length of SAR treatment. As many of the disease progression mechanisms in AD and PD are shared with those in epilepsy, we began to investigate SFK inhibition by SAR in epilepsy models before the onset of epilepsy as a preventative approach $[70,72]$.

We showed that SAR treatment $(25 \mathrm{mg} / \mathrm{kg}$ twice a day for three days followed by once a day for four days) shortly after the initiation of SE by KA in rats reduced the occurrence of SRS, spike frequency, as well as proinflammatory cytokines in the hippocampus and serum [68]. Another study also found reduced SRS and neuronal loss in SAR-treated animals following SE induced by pilocarpine [69]. This led to the hypothesis that SAR might be effective in preventing epileptogenesis and neurodegeneration in DFP-induced SE models too. We recently tested SAR in animals that had $20 \mathrm{~min}$ CS during SE and found that at eight days post-challenge, there was a reduction in SRS while handling during the 
treatment period, as well as gliosis and neurodegeneration [70]. However, in the previous study, we found increased morbidity in SAR-treated animals that had severe SE compared to the VEH-treated animals due to the repeated dosing regimens. Therefore, we decided to reduce the dose of SAR in the current study and tested SAR in both $1 \mathrm{~h}$ and $\sim 30 \mathrm{~min}$ SE models to determine the therapeutic potential of the drug.

Our previous studies showed a reduction of SRS in SAR-treated animals, which were recorded while handling during the treatment period $[68,69]$. Seizures can occur during handling due to the stress of injections, oral gavage, and experimenter fear. Stress increases cortisol levels, which promotes epileptogenesis [100-102]. Though the handling method does provide a snapshot of seizure activity, continuous video EEG would be ideal for a robust assessment as we did in our previous studies [103,104]. In this study, we found a reduction in the number of animals that had at least one CS regardless of SE duration. Notably, in animals with $\sim 60$ min CS, none of the SAR-treated males and $17 \%$ of the SARtreated females had at least one CS. This could be due to a sex difference in the SAR efficacy but could also be due to the increased dose of DFP ( $5 \mathrm{mg} / \mathrm{kg}$ vs. $4 \mathrm{mg} / \mathrm{kg}$ ), though notably, there was no difference in SE severity between sexes. The rationale for increasing the dose of DFP in females in this study was due to the decreased SE severity to the DFP (that we had at that time in our previous studies [26]. Whether the variability in response to DFP in females was due to the source of DFP or vendors or housing (females were housed in a separate room than males in this study) needs further investigation.

Though seizure activity is the primary measurement of interest when studying epilepsy, gliosis and neurodegeneration are also important disease hallmarks [42,48,105-108]. DFP, like other OPNAs, leads to the development of SE through the irreversible inhibition of AchE [109]. SE, regardless of etiology, leads to gliosis and neurodegeneration, which in turn contributes to epileptogenesis [110-112]. In this study, when the animals were given MDZ one hour after DFP and sacrificed at eight days, there was significant upregulation of microgliosis, astrogliosis, and neurodegeneration in all regions of the brain as expected in the DFP model $[26,28,30,31,70,113]$. However, in this group of rats, there was a limited impact of SAR on gliosis and neurodegeneration. We found a significant reduction in the number of IBA1 positive cells in the female AMY and a reduction in reactive astrogliosis in males (in the hippocampus). This finding indicates that there may be a sex difference in the efficacy of SAR in mitigating DFP-induced reactive astrogliosis. This could also be the consequence of the increased dose used in females, although they did have equal initial SE severity compared to males. Notably, astrocytes contain a large number of receptors for gonadal hormones, including those for estrogen (ER $\alpha$ and $\operatorname{Er} \beta$ ), which controls the intracellular calcium levels [114,115]. Perhaps hormonal differences between males and females play a role in determining the efficacy of SAR, which requires further studies. Furthermore, it is unclear whether a prolonged washout time is required to determine the real effects of SAR.

Having observed a limited effect of SAR treatment (for a week) in the $1 \mathrm{~h} \mathrm{SE}$ model, we decided to reduce the duration of SE to understand whether the SE severity impacts SAR efficacy while maintaining the treatment duration for a week ( 20 min group). Interestingly, in this cohort, DFP only led to a significant increase in gliosis and neurodegeneration in the PC and AMY region, not in the hippocampus, which was similar to the findings at day eight post-DFP in our recent study [70]. Traditionally, the hippocampus has been considered the focal point of epileptogenesis in animal models and humans [116-118]. Due to the interconnected nature of the brain regions studied, it would be reasonable to assume that the neuronal and glial changes may spread to other brain regions over time as the disease progresses $[119,120]$. However, our study suggests that in the $20 \mathrm{~min}$ of SE in the DFP model, the damage is limited to the PC/AMY region and not the hippocampus.

SAR treatment for a week significantly reduced gliosis and neurodegeneration in the PC and AMY compared to the VEH-treated animals in 10 weeks post-DFP group. The two cohorts of animals used in this study (8 days post-DFP and 10 weeks post-DFP) were only different in initial SE severity and the time point of sacrifice post-DFP. It is possible 
that SAR treatment had an overall "washout" effect in 10 weeks post-DFP group and mitigated pathology. More likely, however, the overall reduction in SE duration improved the efficacy of SAR in mitigating gliosis and neurodegeneration. Our previous study and the studies from others have shown that the degree of neuropathology depends on the initial SE severity and duration [30,38,70], suggesting that SAR's efficacy also depends on the initial SE severity in epilepsy. As hippocampal sclerosis is common in human patients with temporal lobe epilepsy, it would be useful to further optimize SAR efficacy by extending the duration of its dosing regimen in animals with longer SE to target the hippocampus [121,122].

Prior to euthanasia, we assessed the second cohort of animals ( 20 min CS) for behavioral comorbidities, as epilepsy is associated with changes in learning, memory, anxiety, depression, and motor coordination [123-126]. Importantly, none of these tests, nor brain pathology, showed significant changes in animals treated with SAR on its own (without DFP challenge). This suggests that there were no obvious side effects of SAR treatment per se with the dosing regimen tested in this study. We used the novel object test as well as the MWM to assess learning and memory. Overall, most of these tests did not reveal significant effects nor significant mitigation of DFP-induced toxicity by SAR, but we still find it useful to discuss the trends in the context of other studies.

The novel object test primarily involves the hippocampus for object recognition and memory consolidation $[127,128]$. In the novel object recognition test, we saw a nonsignificant $(p=0.09)$ reduction in the discrimination index in DFP-treated animals. Since the hippocampus was largely unaffected in the 20 min SE group, it is likely that other brain regions may have a role in object recognition. For example, one study found that infusing norepinephrine into the basolateral AMY led to enhanced long-term memory retention and that blocking with propranolol impaired object recognition [129]. Perhaps SE-induced injury to the AMY by DFP may have affected performance in the novel object recognition test. There was mitigation (not significant) by SAR when animals were tested $3 \mathrm{~h}$ after familiarization in the novel object test. However, modification of the NOR test may yield better outcomes, which are currently under investigation. Further tests are needed to make conclusions about its disease modifying effect.

In the MWM, there was no difference in the learning curve between groups, which contradicts previous studies from other groups showing reduced learning in animals exposed to OPs or other chemoconvulsants [130-132]. Since $20 \mathrm{~min}$ was not enough to cause significant hippocampal damage in the rat DFP model, and MWM is also a hippocampaldependent task, we did not observe any differences in the test results [133-135]. Notably, DFP- and SAP-treated animals did spend significantly more time in the target quadrant compared to the opposite quadrant, which suggests some interaction between DFP and SAR and memory consolidation. This needs to be explored further.

We utilized the forced swim test to assess anxiety and depression in these animals [77]. Interestingly, there were no differences between the groups in the forced swim test, which conflicts with previous studies that the animals exposed to chemocovulsants were more immobile [136]. Notably, we used an apparatus with a larger diameter $(28 \mathrm{~cm}$ versus $20 \mathrm{~cm})$ than previously reported, which may have allowed the animals to swim in a wider area. The apparatus in our study was also opaque, and animals were tracked from above rather than from a transparent cylinder from the side [137]. This may have led to differences in the sensitivity of tracking immobility. Future experiments may be needed with a smaller diameter apparatus with an additional camera from the side.

The horizontal bar test is typically used to assess motor ability by measuring the number of foot slips or the time taken to reach the target while an animal is walking across the beam [138]. We did not find an effect of treatment on the number of foot slips, which indicates that DFP-induced SE does not lead to changes in motor ability. This is confirmed by the lack of difference between groups in the rotarod, which is a well-accepted measure of motor ability in rodents [139]. By observation, it appeared that many of the rats fell off the rod due to distraction rather than a lack of ability to stay on the beam. Future tests might 
extend the training period or change the initial speed to mitigate these effects. Furthermore, of note, in the horizontal bar test, all treatment groups improved their time to reach the safety box on the first day compared to the second day, which suggests there was no effect of treatment on motor learning. There is some evidence that epilepsy leads to a change in motor ability, though mostly in children [126,140]. Possibly, there is no change in gross motor behavior in these animals, or the deficits are more present in fine motor skills.

In the horizontal bar test, we did observe that on the $2 \mathrm{~cm}$ beam, DFP-treated animals reached the platform significantly faster. We interpret this as an increased fear of the height (anxiety), driving the animals to reach the platform more quickly or increased impulsivity. Once trained, control animals were more likely to stop and explore their surroundings on the beam before moving to the platform. This is exhibited in both the time to reach the platform as well as the number of pushes by an experimenter. A mouse study showed that the neurons in the basolateral AMY responds to height [141]. Although we did not quantify the subregions of AMY, it is likely that the loss of neurons in the AMY in our model extinguished the fear and anxiety in these animals. The AMY consists of a number of interconnected nuclei [142]. There was no difference in the time to the safety box when animals were later tested on the $1 \mathrm{~cm}$ beam, likely because the bar was too small for even controls of this age to walk across without many experimenters pushing. Overall, assessment of behavioral comorbidities showed some deficits in the animals exposed to DFP and minimal mitigation by SAR.

Overall, in animals with 20 min CS, SAR mitigated CS during handling, neuroinflammation, neurodegeneration, and non-significantly reduced some behavioral comorbidities. Many studies have investigated the glial and neuronal mechanisms of SFKs in disease onset and progression, and we have recently reviewed the previous work and discussed the mitigation strategies by SFK inhibitors [48]. In neurons, Fyn kinase can modulate glutamatergic receptors, including NMDARs (NR2A and NR2B subunits), as well as metabotropic glutamatergic receptors, which contribute to hyperexcitability [49,52,55,143]. Fyn is known to phosphorylate tau, which facilitates the migration of the Fyn-Tau complex to the synaptic site and phosphorylates the glutamatergic receptors [53]. In addition to glutamatergic signaling, Fyn can also modulate GABAergic receptors function, which plays a role in the regulation of seizure activity [144].

In glial cells, Fyn and Src are implicated in neuroinflammation pathways following neurological insult. For example, phosphorylated Fyn and Src interact with the Pyk2/paxillin complex, which is essential for microglial migration $[145,146]$. Therefore, inhibition of SFKs could prevent microglia from becoming reactive, following injury, to protect vulnerable neurons. In a PD model, it was shown that phosphorylated Fyn could activate PKC $\delta$, which leads to translocation of NFKB to the nucleus [58,147]. NFKB mediates the transcription of several genes, including proinflammatory cytokines and mediators of oxidative stress such as iNOS and NADPH oxidase (NOX) $[59,61,148,149]$. These findings led to the hypothesis that anti-oxidant pathways play a role in SAR-mediated mitigation of DFP-induced toxicity. Therefore, we utilized IHC and Western blotting to determine the impact of DFP and SAR on the markers of oxidative stress. As we only detected changes in gliosis and neurodegeneration in the PC/AMY region, we focused our analysis of oxidative stress on these regions.

iNOS is one of three isoforms of NOS, which converts L-arginine to nitric oxide (NO) [150]. iNOS, in contrast to other isoforms (nNOS and eNOS), is not constitutively active and produces high concentrations of NO in short pulses in response to injury [151,152]. We have previously shown the upregulation of iNOS following DFP intoxication and mitigation by an iNOS inhibitor, $1400 \mathrm{~W}$ [28]. Notably, Src phosphorylates iNOS and stabilizes its half-life, which might contribute to iNOS-mediated toxicity [153]. Future studies are required to understand the post-translational modifications of iNOS and mitigation by SAR. In this study, we showed the upregulation of iNOS in both the PC and AMY and, usually, iNOS positive cells were found in clusters within these regions. There was also an increase in 3-NT in both the PC and AMY though it was only significant in the PC, opposite to 
what we found with iNOS. 3-NT is a post-translational modification in which a $\mathrm{NO}_{2}$ group is added to various proteins [154]. NO, which can be generated by NOS, can be further oxidized to $\mathrm{NO}_{2}$, meaning that the presence of iNOS should also lead to increased 3NT levels. Possibly the NO produced by iNOS-positive cells elsewhere, for example, the neighboring AMY, may contribute to higher levels of 3-NT in PC. Alternatively, NO production mediated by nNOS and eNOS may also contribute to the increased 3-NT levels. GP91phox is the catalytic subunit of NADPH oxidase (NOX). NOX2 is predominantly expressed in the brain [155]. Following neurological insult, other cytosolic domains form a complex with membrane-bound GP91 phox, leading to the transfer of an electron to oxygen to form the free radical peroxide $\left(\mathrm{O}_{2}{ }^{-}\right)[156,157]$. In this study, we found a non-significant increase in GP91 ${ }^{\text {phox }}$ in both the AMY and PC, which aligns with previous studies. Similar to iNOS, 3NT and GP91 ${ }^{\text {phox }}$ were also typically found in clusters within the PC/AMY. This might explain why there were no significant differences in 3-NT or GP91 ${ }^{\text {phox }}$ following Western blotting. The entire PC/AMY region was dissected, which likely diluted the effects of clustered upregulation of these markers. There was mitigation by SAR in most of these regions for the presence of these markers, which suggests that SFKs play a role in the upregulation of oxidants following exposure to DFP. We measured these markers ten weeks after DFP intoxication (9 weeks post-cessation of SAR administration), which implies that there was SAR-induced mitigation of DFP-induced oxidative stress that persisted well past the point of administration.

All three of the markers that we tested (iNOS, 3-NT and GP91 ${ }^{\text {phox }}$ ) are considered to be valid markers of oxidative stress and the presence of free radicals. Free radicals such as NO and $\mathrm{O}_{2}{ }^{-}$are essential for many cellular processes, including homeostasis, cellular growth, metabolism, and much more $[158,159]$. In the context of neurological disease, however, these regulators can become deleterious $[160,161]$. For example, $\mathrm{NO}$ and $\mathrm{O}_{2}{ }^{-}$can form peroxynitrite $\left(\mathrm{ONOO}^{-}\right)$, which can nitrosylate proteins and lead to the misregulation of important signaling pathways [152]. Free radicals contribute to neuroinflammation, which in turn exacerbates seizures [162]. We, therefore, hypothesized that these markers might be correlated with the degree of glial activation. In many regions, there was a correlation between these markers of oxidative stress and glial morphology, which supports our hypothesis, especially in the DFP and VEH groups.

\section{Conclusions}

In summary, the goal of this study was to determine the disease-modifying effects of SAR, an SFK inhibitor, in mitigating the neurotoxic effects of DFP-induced SE. We found that the severity and duration of SE and the duration of SAR treatment are important factors to determine the therapeutic potential of the drug. Two cohorts of animals were used in this study. In one group, animals had about an hour SE; in this group, there was a minimal impact of SAR on DFP-induced toxicity due to prolonged duration of CS and a week-long SAR treatment with only $24 \mathrm{~h}$ washout time. Future studies with long-term treatment may increase the efficacy of SAR. Alternatively, SAR could be introduced into the diet instead of direct oral dosing. In animals with about $20 \mathrm{~min}$ SE, SAR mitigated DFP-induced changes in gliosis and neurodegeneration. SAR appears to induce neuroprotective effects, at least in part, via an antioxidant mechanism.

Supplementary Materials: The following are available online at https:/ / www.mdpi.com/article/ 10.3390/antiox11010061/s1, Figure S1: No evidence of pre-existing preference for objects used in the novel object recognition test. Figure S2: Western blotting 3-NT and GP91phox. Table S1: List of antibody and antibody concentrations. Tables S2-S4: Summary of correlational data.

Author Contributions: M.G. (Meghan Gage) performed the animal experiments, collected, analyzed, and verified the data and drafted and edited the manuscript. M.P. conducted animal experiments. L.W., K.D., M.G. (Megan Gard) and C.G.-E. analyzed and verified data. T.T. conceptualized the study, secured funding and edited the figures and manuscript. All authors have read and agreed to the published version of the manuscript. 
Funding: This research was funded by the National Institute of Health/NINDS-CounterACT program (NS110648). AstraZeneca supplied SAR through the Open Innovation Program.

Institutional Review Board Statement: The study was conducted according to the guidelines of the Institutional Care and Use Committee (IACUC-21-109).

Informed Consent Statement: Not applicable.

Data Availability Statement: The data will be made available by the authors following an email to the corresponding author: tswamy@iastate.edu. The data are not publicly available due to a pending $\mathrm{PhD}$ thesis.

Acknowledgments: AstraZeneca supplied SAR through the Open Innovation Program.

Conflicts of Interest: The authors declare no conflict of interest.

\section{References}

1. Newmark, J. Nerve agents. In Clinical Neurotoxicology: Syndromes, Substances, Environments; Elsevier Inc.: Amsterdam, The Netherlands, 2009; pp. 646-659, ISBN 9780323052603.

2. Richardson, J.R.; Fitsanakis, V.; Westerink, R.H.S.; Kanthasamy, A.G. Neurotoxicity of pesticides. Acta Neuropathol. 2019, 138, 343-362. [CrossRef] [PubMed]

3. Yanagisawa, N.; Morita, H.; Nakajima, T. Sarin experiences in Japan: Acute toxicity and long-term effects. J. Neurol. Sci. 2006, 249, 76-85. [CrossRef]

4. Sidell, F.R.; Borak, J. Chemical warfare agents: II. Nerve agents. Ann. Emerg. Med. 1992, 21, 865-871. [CrossRef]

5. Jett, D.A. Neurological aspects of chemical terrorism. Ann. Neurol. 2007, 61, 9-13. [CrossRef] [PubMed]

6. Coupland, R.; Leins, K.-R. Science and prohibited weapons. Science 2005, 308, 1841. [CrossRef]

7. Mukherjee, S.; Gupta, R.D. Organophosphorus Nerve Agents: Types, Toxicity, and Treatments. J. Toxicol. 2020, 2020 , 1-16. [CrossRef]

8. Moshiri, M.; Darchini-Maragheh, E.; Balali-Mood, M. Advances in toxicology and medical treatment of chemical warfare nerve agents. DARU J. Pharm. Sci. 2012, 20, 81. [CrossRef]

9. Robb, E.L.; Baker, M.B. Organophosphate Toxicity; StatPearls Publishing: Treasure Island, FL, USA, 2021.

10. Sawyer, T. Toxicity of organophosphate nerve agents and related phosphonylated oximes compared to their anticholinesterase activity in neuron cultures. Fundam. Appl. Toxicol. 1991, 17, 208-214. [CrossRef]

11. Bajgar, J. Organophosphates\{plus 45 degree rule\}Nerve Agent Poisoning: Mechanism of Action, Diagnosis, Prophylaxis, and Treatment. Adv. Clin. Chem. 2004, 38, 151-216.

12. Bird, S.B. Cholinergic Toxicity. DeckerMed Med. 2015. [CrossRef]

13. Senanayake, N. Organophosporous Insecticide Poisoning. Electron. J. Int. Fed. Clin. Chem. Lab. 1999, 11, 30.

14. Eddleston, M.; Buckley, N.A.; Eyer, P.; Dawson, A.H. Management of acute organophosphorus pesticide poisoning. Lancet 2008, 371,597-607. [CrossRef]

15. McDonough, J.H.; Shih, T.-M. Neuropharmacological Mechanisms of Nerve Agent-induced Seizure and Neuropathology. Neurosci. Biobehav. Rev. 1997, 21, 559-579. [CrossRef]

16. Shih, T.-M.; Rowland, T.C.; McDonough, J.H. Anticonvulsants for nerve agent-induced seizures: The influence of the therapeutic dose of atropine. J. Pharmacol. Exp. Ther. 2007, 320, 154-161. [CrossRef]

17. Seinfeld, S.; Goodkin, H.P.; Shinnar, S. Status epilepticus. Cold Spring Harb. Perspect. Med. 2016, 6, a022830. [CrossRef] [PubMed]

18. Seidenberg, M.; Pulsipher, D.T.; Hermann, B. Association of epilepsy and comorbid conditions. Future Neurol. 2009, 4, 663-668. [CrossRef] [PubMed]

19. Aroniadou-Anderjaska, V.; Figueiredo, T.H.; Apland, J.P.; Prager, E.M.; Pidoplichko, V.I.; Miller, S.L.; Braga, M.F.M. Long-term neuropathological and behavioral impairments after exposure to nerve agents. Ann. N. Y. Acad. Sci. 2016, 1374, 17-28. [CrossRef]

20. Guignet, M.; Dhakal, K.; Flannery, B.M.; Hobson, B.A.; Zolkowska, D.; Dhir, A.; Bruun, D.A.; Li, S.; Wahab, A.; Harvey, D.J.; et al. Persistent behavior deficits, neuroinflammation, and oxidative stress in a rat model of acute organophosphate intoxication. Neurobiol. Dis. 2019, 133, 104431. [CrossRef] [PubMed]

21. Hermann, B.; Seidenberg, M. Epilepsy and Cognition. Epilepsy Curr. 2007, 7, 1-6. [CrossRef]

22. Puttachary, S.; Sharma, S.; Stark, S.; Thippeswamy, T. Seizure-induced oxidative stress in temporal lobe epilepsy. Biomed Res. Int. 2015, 2015, 745613. [CrossRef]

23. Losi, G.; Cammarota, M.; Carmignoto, G. The Role of Astroglia in the Epileptic Brain. Front. Pharmacol. 2012, 3, 132. [CrossRef]

24. Rana, A.; Musto, A.E. The role of inflammation in the development of epilepsy. J. Neuroinflamm. 2018, 15, 1-12. [CrossRef]

25. Farrell, J.S.; Wolff, M.D.; Teskey, G.C. Neurodegeneration and Pathology in Epilepsy: Clinical and Basic Perspectives. Neurodegener. Dis. 2017, 15, 317-334.

26. Gage, M.; Golden, M.; Putra, M.; Sharma, S.; Thippeswamy, T. Sex as a biological variable in the rat model of diisopropylfluorophosphate-induced long-term neurotoxicity. Ann. N. Y. Acad. Sci. 2020, 1479, 44-64. [CrossRef] 
27. Putra, M.; Gage, M.; Sharma, S.; Gardner, C.; Gasser, G.; Anantharam, V.; Thippeswamy, T. Diapocynin, an NADPH oxidase inhibitor, counteracts diisopropylfluorophosphate-induced long-term neurotoxicity in the rat model. Ann. N. Y. Acad. Sci. 2020, 1479, 75. [CrossRef] [PubMed]

28. Putra, M.; Sharma, S.; Gage, M.; Gasser, G.; Hinojo-Perez, A.; Olson, A.; Gregory-Flores, A.; Puttachary, S.; Wang, C.; Anantharam, V.; et al. Inducible nitric oxide synthase inhibitor, $1400 \mathrm{~W}$, mitigates DFP-induced long-term neurotoxicity in the rat model. Neurobiol. Dis. 2019, 133, 104443. [CrossRef] [PubMed]

29. Rojas, A.; Wang, W.; Glover, A.; Manji, Z.; Fu, Y.; Dingledine, R. Beneficial Outcome of Urethane Treatment Following Status Epilepticus in a Rat Organophosphorus Toxicity Model. eNeuro 2018, 5. [CrossRef] [PubMed]

30. Kuruba, R.; Wu, X.; Reddy, D.S. Benzodiazepine-refractory status epilepticus, neuroinflammation, and interneuron neurodegeneration after acute organophosphate intoxication. Biochim. Biophys. Acta Mol. Basis Dis. 2018, 1864, 2845-2858. [CrossRef] [PubMed]

31. Flannery, B.M.; Bruun, D.A.; Rowland, D.J.; Banks, C.N.; Austin, A.T.; Kukis, D.L.; Li, Y.; Ford, B.D.; Tancredi, D.J.; Silverman, J.L.; et al. Persistent neuroinflammation and cognitive impairment in a rat model of acute diisopropylfluorophosphate intoxication. $J$. Neuroinflamm. 2016, 13, 267. [CrossRef] [PubMed]

32. Deshpande, L.S.; Carter, D.S.; Blair, R.E.; DeLorenzo, R.J. Development of a Prolonged Calcium Plateau in Hippocampal Neurons in Rats Surviving Status Epilepticus Induced by the Organophosphate Diisopropylfluorophosphate. Toxicol. Sci. 2010, 116, 623-631. [CrossRef]

33. Eddleston, M.; Szinicz, L.; Eyer, P.; Buckley, N. Oximes in acute organophosphorus pesticide poisoning: A systematic review of clinical trials. QJM 2002, 95, 275-283. [CrossRef]

34. Eddleston, M.; Singh, S.; Buckley, N. Organophosphorus poisoning (acute). BMJ Clin. Evid. 2007, $2007,2102$.

35. Eyer, P. The role of oximes in the management of organophosphorus pesticide poisoning. Toxicol. Rev. 2003, 22, 165-190. [CrossRef]

36. Garcia, G.E.; Campbell, A.J.; Olson, J.; Moorad-Doctor, D.; Morthole, V.I. Novel oximes as blood-brain barrier penetrating cholinesterase reactivators. Chem. Biol. Interact. 2010, 187, 199-206. [CrossRef] [PubMed]

37. Melchers, B.P.C.; Philippens, I.H.; Wolthuis, O.L. Efficacy of HI-6 and HLö-7 in preventing incapacitation following nerve agent poisoning. Pharmacol. Biochem. Behav. 1994, 49, 781-788. [CrossRef]

38. Wu, X.; Kuruba, R.; Reddy, D.S. Midazolam-Resistant Seizures and Brain Injury after Acute Intoxication of Diisopropylfluorophosphate, an Organophosphate Pesticide and Surrogate for Nerve Agents. J. Pharmacol. Exp. Ther. 2018, 367, 302-321. [CrossRef]

39. Miller, S.A.; Blick, D.W.; Kerenyi, S.Z.; Murphy, M.R. Efficacy of physostigmine as a pretreatment for organophosphate poisoning. Pharmacol. Biochem. Behav. 1993, 44, 343-347. [CrossRef]

40. Albuquerque, E.X.; Pereira, E.F.R.; Aracava, Y.; Fawcett, W.P.; Oliveira, M.; Randall, W.R.; Hamilton, T.A.; Kan, R.K.; Romano, J.A.; Adler, M. Effective countermeasure against poisoning by organophosphorus insecticides and nerve agents. Proc. Natl. Acad. Sci. USA 2006, 103, 13220-13225. [CrossRef] [PubMed]

41. Bruun, D.A.; Guignet, M.; Harvey, D.J.; Lein, P.J. Pretreatment with pyridostigmine bromide has no effect on seizure behavior or 24 hour survival in the rat model of acute diisopropylfluorophosphate intoxication. Neurotoxicology 2019, 73, 81-84. [CrossRef]

42. Gilhus, N.E.; Deuschl, G. Neuroinflammation-A common thread in neurological disorders. Nat. Rev. Neurol. 2019, 15, 429-430. [CrossRef]

43. Vitaliti, G.; Pavone, P.; Mahmood, F.; Nunnari, G.; Falsaperla, R. Targeting inflammation as a therapeutic strategy for drug-resistant epilepsies: An update of new immune-modulating approaches. Hum. Vaccines Immunother. 2014, 10, 868-875. [CrossRef]

44. Grant, S. Analysis of NMDA receptor mediated synaptic plasticity using gene targeting: Roles of Fyn and FAK non-receptor tyrosine kinases. J. Physiol. 1996, 90, 337-338. [CrossRef]

45. Lu, Y.F.; Kojima, N.; Tomizawa, K.; Moriwaki, A.; Matsushita, M.; Obata, K.; Matsui, H. Enhanced synaptic transmission and reduced threshold for LTP induction in fyn-transgenic mice. Eur. J. Neurosci. 1999, 11, 75-82. [CrossRef] [PubMed]

46. Arnaud, L.; Ballif, B.A.; Förster, E.; Cooper, J.A. Fyn tyrosine kinase is a critical regulator of Disabled-1 during brain development. Curr. Biol. 2003, 13, 9-17. [CrossRef]

47. Grant, S.G.N.; O'Dell, T.J.; Karl, K.A.; Stein, P.L.; Soriano, P.; Kandel, E.R. Impaired long-term potentiation, spatial learning, and hippocampal development in fyn mutant mice. Science 1992, 258, 1903-1910. [CrossRef] [PubMed]

48. Gage, M.C.; Thippeswamy, T. Inhibitors of Src Family Kinases, Inducible Nitric Oxide Synthase, and NADPH Oxidase as Potential CNS Drug Targets for Neurological Diseases. CNS Drugs 2021, 35, 1-20. [CrossRef]

49. Jin, D.Z.; Mao, L.M.; Wang, J.Q. An essential role of fyn in the modulation of metabotropic glutamate receptor 1 in neurons eNeuro 2017, 4, 4. [CrossRef]

50. Suh, Y.H.; Chang, K.; Roche, K.W. Metabotropic glutamate receptor trafficking. Mol. Cell. Neurosci. 2018, 91, 10-24. [CrossRef]

51. Trepanier, C.H.; Jackson, M.F.; MacDonald, J.F. Regulation of NMDA receptors by the tyrosine kinase Fyn. FEBS J. 2012, 279, 12-19. [CrossRef] [PubMed]

52. Putra, M.; Puttachary, S.; Liu, G.; Lee, G.; Thippeswamy, T. Fyn-tau Ablation Modifies PTZ-Induced Seizures and Post-seizure Hallmarks of Early Epileptogenesis. Front. Cell. Neurosci. 2020, 14, 592374. [CrossRef]

53. Ittner, L.M.; Ke, Y.D.; Delerue, F.; Bi, M.; Gladbach, A.; van Eersel, J.; Wölfing, H.; Chieng, B.C.; Christie, M.J.; Napier, I.A.; et al. Dendritic function of tau mediates amyloid- $\beta$ toxicity in alzheimer's disease mouse models. Cell 2010, 142, 387-397. [CrossRef] 
54. Miyamoto, T.; Stein, L.; Thomas, R.; Djukic, B.; Taneja, P.; Knox, J.; Vossel, K.; Mucke, L. Phosphorylation of tau at Y18, but not tau-fyn binding, is required for tau to modulate NMDA receptor-dependent excitotoxicity in primary neuronal culture. Mol. Neurodegener. 2017, 12,1-19. [CrossRef]

55. Knox, R.; Jiang, X. Fyn in Neurodevelopment and Ischemic Brain Injury. Dev. Neurosci. 2015, 37, 311-320. [CrossRef]

56. Boehm, S.L.; Peden, L.; Harris, R.A.; Blednov, Y.A. Deletion of the fyn-kinase gene alters sensitivity to GABAergic drugs: Dependence on $\beta 2 / \beta 3$ GABAA receptor subunits. J. Pharmacol. Exp. Ther. 2004, 309, 1154-1159. [CrossRef]

57. Sharma, S.; Carlson, S.; Puttachary, S.; Sarkar, S.; Showman, L.; Putra, M.; Kanthasamy, A.G.; Thippeswamy, T. Role of the Fyn-PKC $\delta$ signaling in SE-induced neuroinflammation and epileptogenesis in experimental models of temporal lobe epilepsy. Neurobiol. Dis. 2018, 110, 102-121. [CrossRef]

58. Panicker, N.; Saminathan, H.; Jin, H.; Neal, M.; Harischandra, D.S.; Gordon, R.; Kanthasamy, K.; Lawana, V.; Sarkar, S.; Luo, J.; et al. Fyn kinase regulates microglial neuroinflammatory responses in cell culture and animal models of parkinson's disease. $J$. Neurosci. 2015, 35, 10058-10077. [CrossRef] [PubMed]

59. Shih, R.H.; Wang, C.Y.; Yang, C.M. NF-kappaB signaling pathways in neurological inflammation: A mini review. Front. Mol. Neurosci. 2015, 8, 77. [CrossRef] [PubMed]

60. Clark, R.A.; Valente, A.J. Nuclear factor kappa B activation by NADPH oxidases. Mech. Ageing Dev. 2004, 125, 799-810. [CrossRef] [PubMed]

61. Liu, T.; Zhang, L.; Joo, D.; Sun, S.C. NF-кB signaling in inflammation. Signal Transduct. Target. Ther. 2017, 2, 17023. [CrossRef]

62. McNeish, I.A.; Ledermann, J.A.; Webber, L.; James, L.; Kaye, S.B.; Hall, M.; Hall, G.; Clamp, A.; Earl, H.; Banerjee, S.; et al. A randomised, placebo-controlled trial of weekly paclitaxel and saracatinib (AZD0530) in platinum-resistant ovarian, fallopian tube or primary peritoneal cancer. Ann. Oncol. 2014, 25, 1988-1995. [CrossRef]

63. Molina, J.R.; Foster, N.R.; Reungwetwattana, T.; Nelson, G.D.; Grainger, A.V.; Steen, P.D.; Stella, P.J.; Marks, R.; Wright, J.; Adjei, A.A. A phase II trial of the Src-kinase inhibitor saracatinib after four cycles of chemotherapy for patients with extensive stage small cell lung cancer: NCCTG trial N-0621. Lung Cancer 2014, 85, 245-250. [CrossRef]

64. Dhawan, G.; Combs, C.K. Inhibition of Src kinase activity attenuates amyloid associated microgliosis in a murine model of Alzheimer's disease. J. Neuroinflamm. 2012, 9, 563. [CrossRef] [PubMed]

65. Panicker, N.; Kanthasamy, A.; Kanthasamy, A.G. Fyn amplifies NLRP3 inflammasome signaling in Parkinson's disease. Aging 2019, 11, 5871-5873. [CrossRef] [PubMed]

66. Yang, H.; Wang, L.; Zang, C.; Wang, Y.; Shang, J.; Zhang, Z.; Liu, H.; Bao, X.; Wang, X.; Zhang, D. Src Inhibition Attenuates Neuroinflammation and Protects Dopaminergic Neurons in Parkinson's Disease Models. Front. Neurosci. 2020, 14, 45. [CrossRef]

67. Nygaard, H.B.; Wagner, A.F.; Bowen, G.S.; Good, S.P.; MacAvoy, M.G.; Strittmatter, K.A.; Kaufman, A.C.; Rosenberg, B.J.; Sekine-Konno, T.; Varma, P.; et al. A phase Ib multiple ascending dose study of the safety, tolerability, and central nervous system availability of AZD0530 (saracatinib) in Alzheimer's disease. Alzheimers Res. Ther. 2015, 7, 1-11. [CrossRef] [PubMed]

68. Sharma, S.; Carlson, S.; Gregory-Flores, A.; Hinojo-Perez, A.; Olson, A.; Thippeswamy, T. Mechanisms of disease-modifying effect of saracatinib (AZD0530), a Src/Fyn tyrosine kinase inhibitor, in the rat kainate model of temporal lobe epilepsy. Neurobiol. Dis. 2021, 156, 105410. [CrossRef]

69. Luo, X.-M.; Zhao, J.; Wu, W.-Y.; Fu, J.; Li, Z.-Y.; Zhang, M.; Lu, J. Post-status epilepticus treatment with the Fyn inhibitor, saracatinib, improves cognitive function in mice. BMC Neurosci. 2021, 22, 1-8. [CrossRef] [PubMed]

70. Gage, M.; Putra, M.; Estrada, C.G.; Golden, M.; Wachter, L.; Gard, M.; Thippeswamy, T. Differential impact of severity and duration of status epilepticus, medical countermeasures, and a disease-modifier, saracatinib (AZD0530), on brain regions in the rat diisopropylfluorophosphate (DFP) model. Front. Cell. Neurosci. 2021, 15, 426. [CrossRef] [PubMed]

71. Kilkenny, C.; Browne, W.J.; Cuthill, I.C.; Emerson, M.; Altman, D.G. Improving Bioscience Research Reporting: The ARRIVE Guidelines for Reporting Animal Research. PLoS Biol. 2010, 8, e1000412. [CrossRef]

72. Racine, R.J. Modification of seizure activity by electrical stimulation. II: Motor seizure. Electroencephalogr. Clin. Neurophysiol. 1972, 32, 281-294. [CrossRef]

73. Irwin, S. Comprehensive observational assessment: Ia. A systematic, quantitative procedure for assessing the behavioral and physiologic state of the mouse. Psychopharmacologia 1968, 13, 222-257. [CrossRef] [PubMed]

74. Rojas, A.; Ganesh, T.; Manji, Z.; O'neill, T.; Dingledine, R. Inhibition of the prostaglandin E2 receptor EP2 prevents status epilepticus-induced deficits in the novel object recognition task in rats. Neuropharmacology 2016, 110, 419-430. [CrossRef]

75. Lueptow, L.M. Novel object recognition test for the investigation of learning and memory in mice. J. Vis. Exp. 2017, 2017, 55718. [CrossRef] [PubMed]

76. Pearson, J.N.; Schulz, K.M.; Patel, M. Specific alterations in the performance of learning and memory tasks in models of chemoconvulsant-induced status epilepticus. Epilepsy Res. 2014, 108, 1032-1040. [CrossRef] [PubMed]

77. Yankelevitch-Yahav, R.; Franko, M.; Huly, A.; Doron, R. The forced swim test as a model of depressive-like behavior. J. Vis. Exp. 2015, 2015, 52587. [CrossRef]

78. Cosgrave, A.S.; McKay, J.S.; Bubb, V.; Morris, R.; Quinn, J.P.; Thippeswamy, T. Regulation of activity-dependent neuroprotective protein (ADNP) by the NO-cGMP pathway in the hippocampus during kainic acid-induced seizure. Neurobiol. Dis. 2008, 30, 281-292. [CrossRef] 
79. Beamer, E.; Otahal, J.; Sills, G.J.; Thippeswamy, T. Nw-Propyl-1-arginine (L-NPA) reduces status epilepticus and early epileptogenic events in a mouse model of epilepsy: Behavioural, EEG and immunohistochemical analyses. Eur. J. Neurosci. 2012, 36, 3194-3203. [CrossRef]

80. Streit, W.J.; Walter, S.A.; Pennell, N.A. Reactive microgliosis. Prog. Neurobiol. 1999, 57, 563-581. [CrossRef]

81. Liu, T.; Zhang, M.; Mukosera, G.T.; Borchardt, D.; Li, Q.; Tipple, T.E.; Ahmed, A.S.I.; Power, G.G.; Blood, A.B. L-NAME releases nitric oxide and potentiates subsequent nitroglycerin-mediated vasodilation. Redox Biol. 2019, 26, 101238. [CrossRef]

82. Sántha, P.; Veszelka, S.; Hoyk, Z.; Mészáros, M.; Walter, F.R.; Tóth, A.E.; Deli, M.A. Restraint Stress-Induced Morphological Changes at the Blood-Brain Barrier in Adult Rats. Front. Mol. Neurosci. 2016, 8, 88. [CrossRef]

83. Green, T.P.; Fennell, M.; Whittaker, R.; Curwen, J.; Jacobs, V.; Allen, J.; Logie, A.; Hargreaves, J.; Hickinson, D.M.; Wilkinson, R.W.; et al. Preclinical anticancer activity of the potent, oral Src inhibitor AZD0530. Mol. Oncol. 2009, 3, 248-261. [CrossRef]

84. Fujisaka, Y.; Onozawa, Y.; Kurata, T.; Yasui, H.; Goto, I.; Yamazaki, K.; Machida, N.; Watanabe, J.; Shimada, H.; Shi, X.; et al. First report of the safety, tolerability, and pharmacokinetics of the Src kinase inhibitor saracatinib (AZD0530) in Japanese patients with advanced solid tumours. Investig. New Drugs 2013, 31, 108-114. [CrossRef]

85. Baselga, J.; Cervantes, A.; Martinelli, E.; Chirivella, I.; Hoekman, K.; Hurwitz, H.I.; Jodrell, D.I.; Hamberg, P.; Casado, E.; Elvin, P.; et al. Phase I safety, pharmacokinetics, and inhibition of src activity study of saracatinib in patients with solid tumors. Clin. Cancer Res. 2010, 16, 4876-4883. [CrossRef] [PubMed]

86. Gucal, A.; Sparano, J.; Caravelli, A.; Santamauro, J.; Patil, S.; Abbruzzi, A.; Pellegrino, C.; Bromberg, J.; Dang, C.; Theodoulou, M.; et al. Phase II trial of saracatinib (AZD0530), an oral SRC-inhibitor for the treatment of patients with hormone receptor-negative metastatic breast cancer. Clin. Breast Cancer 2011, 11, 306-311. [CrossRef]

87. Chen, J.; Peng, Y.; Zheng, J. Cytochrome P450 Mediated Bioactivation of Saracatinib. Chem. Res. Toxicol. 2016, 29, 1835-1842. [CrossRef]

88. Attwa, M.; Kadi, A.; Darwish, H.; Alrabiah, H. LC-MS/MS reveals the formation of reactive ortho-quinone and iminium intermediates in saracatinib metabolism: Phase I metabolic profiling. Clin. Chim. Acta 2018, 482, 84-94. [CrossRef] [PubMed]

89. Li, J.; Chen, Y.; Tang, Y.; Li, W.; Tu, Y. Homotropic Cooperativity of Midazolam Metabolism by Cytochrome P450 3A4: Insight from Computational Studies. J. Chem. Inf. Model. 2021, 61, 2418-2426. [CrossRef]

90. Tao, G.; Huang, J.; Moorthy, B.; Wang, C.; Hu, M.; Gao, S.; Ghose, R. Potential role of drug metabolizing enzymes in chemotherapyinduced gastrointestinal toxicity and hepatotoxicity. Expert Opin. Drug Metab. Toxicol. 2020, 16, 1109-1124. [CrossRef]

91. Kaufman, A.C.; Salazar, S.V.; Haas, L.T.; Yang, J.; Kostylev, M.A.; Jeng, A.T.; Robinson, S.A.; Gunther, E.C.; van Dyck, C.H.; Nygaard, H.B.; et al. Fyn Inhibition Rescues Established Memory and Synapse Loss in Alzheimer Mice. Ann. Neurol. 2015, 77, 953. [CrossRef] [PubMed]

92. Kast, R.E.; Focosi, D. Three paths to better tyrosine kinase inhibition behind the blood-brain barrier in treating chronic myelogenous leukemia and glioblastoma with imatinib. Transl. Oncol. 2010, 3, 13-15. [CrossRef]

93. Mittapalli, R.K.; Chung, A.H.; Parrish, K.E.; Crabtree, D.; Halvorson, K.G.; Hu, G.; Elmquist, W.F.; Becher, O.J. ABCG2 and ABCB1 limit the efficacy of dasatinib in a PDGF-B-driven brainstem glioma model. Mol. Cancer Ther. 2016, 15, 819-829. [CrossRef] [PubMed]

94. Smith, L.M.; Zhu, R.; Strittmatter, S.M. Disease-modifying benefit of Fyn blockade persists after washout in mouse Alzheimer's model. Neuropharmacology 2018, 130, 54-61. [CrossRef]

95. Toyonaga, T.; Smith, L.M.; Finnema, S.J.; Gallezot, J.-D.; Naganawa, M.; Bini, J.; Mulnix, T.; Cai, Z.; Ropchan, J.; Huang, Y.; et al. In Vivo Synaptic Density Imaging with 11C-UCB-J Detects Treatment Effects of Saracatinib in a Mouse Model of Alzheimer Disease. J. Nucl. Med. 2019, 60, 1780. [CrossRef]

96. Choi, Y.R.; Kim, J.; Kang, S.; Noh, H.R.; Jou, I.; Joe, E.; Park, S.M. The dual role of c-src in cell-to-cell transmission of $\alpha$-synuclein. EMBO Rep. 2020, 21, e48950. [CrossRef] [PubMed]

97. Posadas, E.M.; Ahmed, R.S.; Karrison, T.; Szmulewitz, R.Z.; O’Donnell, P.H.; Wade, J.L., III; Stadler, W.M. Saracatinib as a metastasis inhibitor in metastatic castration-resistant prostate cancer: A University of Chicago Phase 2 Consortium and DOD/PCF Prostate Cancer Clinical Trials Consortium Study. Prostate 2016, 76, 286-293. [CrossRef]

98. Baird, K.; Glod, J.; Steinberg, S.; Reinke, D.; Pressey, J.; Mascarenhas, L.; Federman, N.; Marina, N.; Chawla, S.; Lagmay, J.; et al. Results of a Randomized, Double-Blinded, Placebo-Controlled, Phase 2.5 Study of Saracatinib (AZD0530), in Patients with Recurrent Osteosarcoma Localized to the Lung. Sarcoma 2020, 2020, 1-6. [CrossRef]

99. Van Dyck, C.H.; Nygaard, H.B.; Chen, K.; Donohue, M.C.; Raman, R.; Rissman, R.A.; Brewer, J.B.; Koeppe, R.A.; Chow, T.W.; Rafii, M.S.; et al. Effect of AZD0530 on Cerebral Metabolic Decline in Alzheimer Disease: A Randomized Clinical Trial. JAMA Neurol. 2019, 76, 1219-1229. [CrossRef] [PubMed]

100. Castro, O.W.; Santos, V.R.; Pun, R.Y.K.; McKlveen, J.M.; Batie, M.; Holland, K.D.; Gardner, M.; Garcia-Cairasco, N.; Herman, J.P.; Danzer, S.C. Impact of corticosterone treatment on spontaneous seizure frequency and epileptiform activity in mice with chronic epilepsy. PLoS ONE 2012, 7, e46044. [CrossRef]

101. Cano-López, I.; González-Bono, E. Cortisol levels and seizures in adults with epilepsy: A systematic review. Neurosci. Biobehav. Rev. 2019, 103, 216-229. [CrossRef]

102. Maguire, J.; Salpekar, J.A. Stress, seizures, and hypothalamic-pituitary-adrenal axis targets for the treatment of epilepsy. Epilepsy Behav. 2013, 26, 352-362. [CrossRef] 
103. Lundt, A.; Wormuth, C.; Siwek, M.E.; Müller, R.; Ehninger, D.; Henseler, C.; Broich, K.; Papazoglou, A.; Weiergräber, M. EEG Radiotelemetry in Small Laboratory Rodents: A Powerful State-of-the Art Approach in Neuropsychiatric, Neurodegenerative, and Epilepsy Research. Neural Plast. 2016, 2016. [CrossRef]

104. Abdullah, J.M.; Islam, M.R. Telemetric EEG and the rat: A guide for neuroscientists. Malays. J. Med. Sci. 2012, 19, 1-5. [PubMed]

105. Zhao, X.; Liao, Y.; Morgan, S.; Mathur, R.; Feustel, P.; Mazurkiewicz, J.; Qian, J.; Chang, J.; Mathern, G.W.; Adamo, M.A.; et al. Noninflammatory Changes of Microglia Are Sufficient to Cause Epilepsy. Cell Rep. 2018, 22, 2080-2093. [CrossRef]

106. Lull, M.E.; Block, M.L. Microglial Activation and Chronic Neurodegeneration. Neurotherapeutics 2010, 7, 354-365. [CrossRef]

107. Tang, Y.; Li, X.; Mao, X. Editorial: Linking Neuroinflammation and Glial Phenotypic Changes in Neurological Diseases. Front. Cell. Neurosci. 2019, 13, 542. [CrossRef]

108. Rao, M.S.; Hattiangady, B.; Reddy, D.S.; Shetty, A.K. Hippocampal neurodegeneration, spontaneous seizures, and mossy fiber sprouting in the F344 rat model of temporal lobe epilepsy. J. Neurosci. Res. 2006, 83, 1088-1105. [CrossRef] [PubMed]

109. Namba, T. Cholinesterase inhibition by organophosphorus compounds and its clinical effects. Bull. World Health Organ. 1971, 44, 289. [PubMed]

110. Barker-Haliski, M.; Löscher, W.; White, H.; Galanopoulou, A. Neuroinflammation in epileptogenesis: Insights and translational perspectives from new models of epilepsy. Epilepsia 2017, 58 (Suppl. S3), 39-47. [CrossRef]

111. Vezzani, A.; French, J.; Bartfai, T.; Baram, T.Z. The role of inflammation in epilepsy. Nat. Rev. Neurol. 2011, 7, 31-40. [CrossRef]

112. Tang, F.; Hartz, A.; Bauer, B. Drug-Resistant Epilepsy: Multiple Hypotheses, Few Answers. Front. Neurol. 2017, 8, 301. [CrossRef]

113. Rojas, A.; Ganesh, T.; Wang, W.; Wang, J.; Dingledine, R. A rat model of organophosphate-induced status epilepticus and the beneficial effects of EP2 receptor inhibition. Neurobiol. Dis. 2019, 133, 104399. [CrossRef]

114. Chaban, V.; Lakhter, A.; Micevych, P. A membrane estrogen receptor mediates intracellular calcium release in astrocytes. Endocrinology 2004, 145, 3788-3795. [CrossRef] [PubMed]

115. Rurak, G.M.; Woodside, B.; Aguilar-Valles, A.; Salmaso, N. Astroglial cells as neuroendocrine targets in forebrain development: Implications for sex differences in psychiatric disease. Front. Neuroendocrinol. 2021, 60, 100897. [CrossRef]

116. Coan, A.C.; Cendes, F. Epilepsy as progressive disorders: What is the evidence that can guide our clinical decisions and how can neuroimaging help? Epilepsy Behav. 2013, 26, 313-321. [CrossRef] [PubMed]

117. Cendes, F. Progressive hippocampal and extrahippocampal atrophy in drug resistant epilepsy. Curr. Opin. Neurol. 2005, 18, 173-177. [CrossRef]

118. Gorter, J.A.; van Vliet, E.A.; Aronica, E.; da Silva, F.H.L. Progression of spontaneous seizures after status epilepticus is associated with mossy fibre sprouting and extensive bilateral loss of hilar parvalbumin and somatostatin-immunoreactive neurons. Eur. J. Neurosci. 2001, 13, 657-669. [CrossRef] [PubMed]

119. Vismer, M.S.; Forcelli, P.A.; Skopin, M.D.; Gale, K.; Koubeissi, M.Z. The piriform, perirhinal, and entorhinal cortex in seizure generation. Front. Neural Circuits 2015, 9, 27. [CrossRef]

120. Yang, Y.; Wang, J.-Z. From Structure to Behavior in Basolateral Amygdala-Hippocampus Circuits. Front. Neural Circuits 2017, 11, 86. [CrossRef] [PubMed]

121. Thom, M.; Eriksson, S.; Martinian, L.; Caboclo, L.O.; McEvoy, A.W.; Duncan, J.S.; Sisodiya, S.M. Temporal Lobe Sclerosis Associated with Hippocampal Sclerosis in Temporal Lobe Epilepsy: Neuropathological Features. J. Neuropathol. Exp. Neurol. 2009, 68, 928. [CrossRef]

122. Henry, T.R.; Chupin, M.; Lehéricy, S.; Strupp, J.P.; Sikora, M.A.; Sha, Z.Y.; Uğurbil, K.; Moortele, P.-F. Van de Hippocampal Sclerosis in Temporal Lobe Epilepsy: Findings at 7 T. Radiology 2011, 261, 199. [CrossRef]

123. England, M.J.; Liverman, C.T.; Schultz, A.M.; Strawbridge, L.M. Epilepsy across the spectrum: Promoting health and understanding.: A summary of the Institute of Medicine report. Epilepsy Behav. 2012, 25, 266-276. [CrossRef] [PubMed]

124. Holmes, G.L. Cognitive impairment in Epilepsy: The Role of Network Abnormalities. Epileptic Disord. 2015, 17, 101. [CrossRef]

125. Jackson, M.J.; Turkington, D. Depression and anxiety in epilepsy. J. Neurol. Neurosurg. Psychiatry 2005, 76, i45-i47. [CrossRef]

126. Simmatis, L.E.R.; Jin, A.Y.; Keiski, M.; Lomax, L.B.; Scott, S.H.; Winston, G.P. Assessing various sensorimotor and cognitive functions in people with epilepsy is feasible with robotics-NC-ND license. Epilepsy Behav. 2020, 103, 106859. [CrossRef]

127. Antunes, M.; Biala, G. The novel object recognition memory: Neurobiology, test procedure, and its modifications. Cogn. Process. 2012, 13, 93-110. [CrossRef]

128. Kadar, T.; Cohen, G.; Sahar, R.; Alkalai, D.; Shapira, S. Long-Term Study of Brain Lesions Following Soman, in Comparison to DFP and Metrazol Poisoning. Hum. Exp. Toxicol. 1992, 11, 517-523. [CrossRef] [PubMed]

129. Barsegyan, A.; McGaugh, J.L.; Roozendaal, B. Noradrenergic activation of the basolateral amygdala modulates the consolidation of object-in-context recognition memory. Front. Behav. Neurosci. 2014, 8, 160. [CrossRef] [PubMed]

130. Yu, X.; Zhou, T.; Yu, H.; Chang, L.Y.; Wei, L.L. Corilagin reduces the frequency of seizures and improves cognitive function in a rat model of chronic epilepsy. Med. Sci. Monit. 2018, 24, 2832-2840. [CrossRef]

131. Shuman, T.; Aharoni, D.; Cai, D.J.; Lee, C.R.; Chavlis, S.; Page-Harley, L.; Vetere, L.M.; Feng, Y.; Yang, C.Y.; Mollinedo-Gajate, I.; et al. Breakdown of spatial coding and interneuron synchronization in epileptic mice. Nat. Neurosci. 2020, 23, 229-238. [CrossRef]

132. Branders, R.; Raveh, L.; Grunwald, J.; Cohen, E.; Ashani, Y. Prevention of soman-induced cognitive deficits by pretreatment with human butyrylcholinesterase in rats. Pharmacol. Biochem. Behav. 1993, 46, 889-896. [CrossRef]

133. D'Hooge, R.; De Deyn, P. Applications of the Morris water maze in the study of learning and memory. Brain Res. Rev. 2001, 36, 60-90. [CrossRef] 
134. Braun, A.A.; Skelton, M.R.; Vorhees, C.V.; Williams, M.T. Comparison of the elevated plus and elevated zero mazes in treated and untreated male Sprague-Dawley rats: Effects of anxiolytic and anxiogenic agents. Pharmacol. Biochem. Behav. 2011, 97, 406-415. [CrossRef]

135. Inostroza, M.; Cid, E.; Brotons-Mas, J.; Gal, B.; Aivar, P.; Uzcateg, Y.G.; Sandi, C.; de la Prida, L.M. Hippocampal-Dependent spatial memory in the water maze is preserved in an experimental model of temporal lobe epilepsy in rats. PLoS ONE 2011, 6, e22372. [CrossRef]

136. Koh, S.; Magid, R.; Chung, H.; Stine, C.D.; Wilson, D.N. Depressive behavior and selective downregulation of serotonin receptor expression after early-life seizures: Reversal by environmental enrichment. Epilepsy Behav. 2007, 10, 26-31. [CrossRef]

137. Bogdanova, O.V.; Kanekar, S.; D'anci, K.E.; Renshaw, P.F.; Author, P.B. Factors influencing behavior in the forced swim test HHS Public Access Author manuscript. Physiol. Behav. 2013, 118, 227-239. [CrossRef]

138. Deacon, R.M.J. Measuring motor coordination in mice. J. Vis. Exp. 2013, 75, e2609. [CrossRef] [PubMed]

139. Buitrago, M.M.; Schulz, J.B.; Dichgans, J.; Luft, A.R. Short and long-term motor skill learning in an accelerated rotarod training paradigm. Neurobiol. Learn. Mem. 2004, 81, 211-216. [CrossRef]

140. Takano, T.; Hayashi, A.; Harada, Y. Progression of motor disability in cerebral palsy: The role of concomitant epilepsy. Seizure 2020, 80, 81-85. [CrossRef]

141. Liu, J.; Lin, L.; Wang, D.V. Representation of Fear of Heights by Basolateral Amygdala Neurons. J. Neurosci. 2021, 41, 1080-1091. [CrossRef] [PubMed]

142. Janak, P.H.; Tye, K.M. From circuits to behaviour in the amygdala. Nature 2015, 517, 284. [CrossRef] [PubMed]

143. Salter, M.W.; Kalia, L.V. SRC kinases: A hub for NMDA receptor regulation. Nat. Rev. Neurosci. 2004, 5, 317-328. [CrossRef]

144. Jurd, R.; Tretter, V.; Walker, J.; Brandon, N.J.; Moss, S.J. Fyn kinase contributes to tyrosine phosphorylation of the GABAA receptor $\gamma 2$ subunit. Mol. Cell. Neurosci. 2010, 44, 129-134. [CrossRef]

145. Fan, Y.; Xie, L.; Chung, C.Y. Signaling pathways controlling microglia chemotaxis. Mol. Cells 2017, 40, 163-168.

146. Lee, S.H.; Hollingsworth, R.; Kwon, H.Y.; Lee, N.; Chung, C.Y. $\beta$-arrestin 2-dependent activation of ERK1/2 is required for ADP-induced paxillin phosphorylation at Ser83 and microglia chemotaxis. Glia 2012, 60, 1366-1377. [CrossRef]

147. Panicker, N.; Sarkar, S.; Harischandra, D.S.; Neal, M.; Kam, T.I.; Jin, H.; Saminathan, H.; Langley, M.; Charli, A.; Samidurai, M.; et al. Fyn kinase regulates misfolded $\alpha$-synuclein uptake and NLRP3 inflammasome activation in microglia. J. Exp. Med. 2019, 216, 1411-1430. [CrossRef]

148. Kaltschmidt, B.; Kaltschmidt, C. NF-kappaB in the nervous system. Cold Spring Harb. Perspect. Biol. 2009, 1, a001271. [CrossRef]

149. Anrather, J.; Racchumi, G.; Iadecola, C. NF-кB regulates phagocytic NADPH oxidase by inducing the expression of gp91phox. J. Biol. Chem. 2006, 281, 5657-5667. [CrossRef]

150. Aktan, F. iNOS-mediated nitric oxide production and its regulation. Life Sci. 2004, 75, 639-653. [CrossRef] [PubMed]

151. Walker, G.; Pfeilschifter, J.; Kunz, D. Mechanisms of suppression of inducible nitric-oxide synthase (iNOS) expression in interferon (IFN)- $\gamma$-stimulated RAW 264.7 cells by dexamethasone. Evidence for glucocorticoid-induced degradation of iNOS protein by calpain as a key step in post-transcriptional regulation. J. Biol. Chem. 1997, 272, 16679-16687. [PubMed]

152. Knott, A.B.; Bossy-Wetzel, E. Nitric oxide in health and disease of the nervous system. Antioxid. Redox Signal. 2009, 11, 541-553. [CrossRef] [PubMed]

153. Tyryshkin, A.; Gorgun, F.; Fattah, E.A.; Mazumdar, T.; Pandit, L.; Zeng, S.; Eissa, N. Src kinase-mediated phosphorylation stabilizes inducible nitric-oxide synthase in normal cells and cancer cells. J. Biol. Chem. 2010, 285, 784-792. [CrossRef]

154. Ahsan, H. 3-Nitrotyrosine: A biomarker of nitrogen free radical species modified proteins in systemic autoimmunogenic conditions. Hum. Immunol. 2013, 74, 1392-1399. [CrossRef]

155. Cooney, S.J.; Bermudez-Sabogal, S.L.; Byrnes, K.R. Cellular and temporal expression of NADPH oxidase (NOX) isotypes after brain injury. J. Neuroinflamm. 2013, 10, 155. [CrossRef]

156. Fuentes, E.; Gibbins, J.M.; Holbrook, L.M.; Palomo, I. NADPH oxidase 2 (NOX2): A key target of oxidative stress-mediated platelet activation and thrombosis. Trends Cardiovasc. Med. 2018, 28, 429-434. [CrossRef]

157. Sharma, S.; Puttachary, S.; Thippeswamy, T. Glial source of nitric oxide in epileptogenesis: A target for disease modification in epilepsy. J. Neurosci. Res. 2017, 97, 1363-1377. [CrossRef] [PubMed]

158. Ray, P.D.; Huang, B.W.; Tsuji, Y. Reactive oxygen species (ROS) homeostasis and redox regulation in cellular signaling. Cell. Signal. 2012, 24, 981-990. [CrossRef]

159. Mittler, R. ROS Are Good. Trends Plant Sci. 2017, 22, 11-19. [CrossRef] [PubMed]

160. Kumar, H.; Lim, H.-W.; More, S.V.; Kim, B.-W.; Koppula, S.; Kim, I.S.; Choi, D.-K. The Role of Free Radicals in the Aging Brain and Parkinson's Disease: Convergence and Parallelism. Int. J. Mol. Sci. 2012, 13, 10478. [CrossRef] [PubMed]

161. Uttara, B.; Singh, A.V.; Zamboni, P.; Mahajan, R. Oxidative Stress and Neurodegenerative Diseases: A Review of Upstream and Downstream Antioxidant Therapeutic Options. Curr. Neuropharmacol. 2009, 7, 65. [CrossRef]

162. Wu, L.; Xiong, X.; Wu, X.; Ye, Y.; Jian, Z.; Zhi, Z.; Gu, L. Targeting Oxidative Stress and Inflammation to Prevent IschemiaReperfusion Injury. Front. Mol. Neurosci. 2020, 13, 28. [CrossRef] 